\title{
Loss of control over eating: A systematic review of task based research into impulsive and compulsive processes in binge eating
}

Maria Waltmann ${ }^{1,2,3 *}$, Nadine Herzog ${ }^{2,3}$, Annette Horstmann ${ }^{2,3,4,5}$, Lorenz Deserno ${ }^{1,2,3}$

\footnotetext{
${ }^{1}$ Department of Child and Adolescent Psychiatry, Psychosomatics and Psychotherapy, Centre of Mental Health, University of Würzburg, Margarete-Höppel-Platz1, 97080 Würzburg, Germany

${ }^{2}$ Max Planck Institute for Human Cognitive and Brain Sciences, Stephanstraße 1, 04103 Leipzig, Germany

${ }^{3}$ IFB Adiposity Diseases, Leipzig University Medical Center, Leipzig, Germany

${ }^{4}$ Department of Psychology and Logopedics, Faculty of Medicine, University of Helsinki, Helsinki, Finland

${ }^{5}$ Medical Faculty, University of Leipzig, Leipzig, Germany

${ }^{*}$ Corresponding author
}

Contact details of corresponding author

Email: $\quad$ waltmann_m@ukw.de

Phone: $\quad$ +49 (0931) 20178700

Fax: $\quad+49(0931) 20178040$ 


\section{Abstract}

Recurring episodes of excessive food intake in binge eating disorder can be understood through the lens of behavioral control systems: patients repeat maladaptive behaviors against their explicit intent. Self-report measures show enhanced impulsivity and compulsivity in binge eating (BE) but are agnostic as to the processes that might lead to impulsive and compulsive behavior in the moment. Task-based neurocognitive investigations can tap into those processes. In this systematic review, we synthesize neurocognitive research on behavioral impulsivity and compulsivity in BE in humans and animals, published between 2010-2020. Findings on impulsivity are heterogeneous. Findings on compulsivity are sparse but comparatively consistent, indicating an imbalance of goal-directed and habitual control as well as deficits in reversal learning. We urge researchers to address heterogeneity related to mood states and the temporal dynamics of symptoms, to systematically differentiate contributions of body weight and BE, and to ascertain the validity and reliability of tasks. Moreover, we propose to further scrutinize the compulsivity findings to unravel the computational mechanisms of a potential reinforcement learning deficit.

Keywords: Binge eating, behavioral control, impulsivity, compulsivity, neurocognitive tasks, computational modeling 


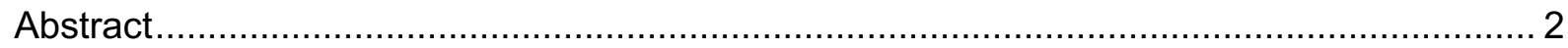

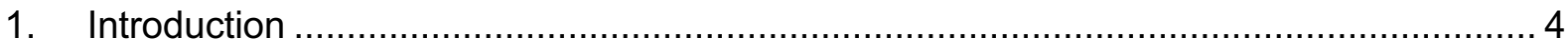

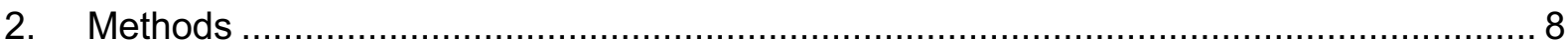

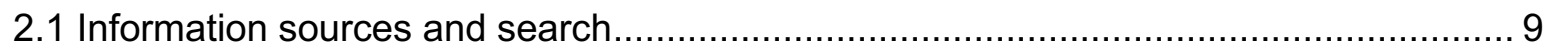

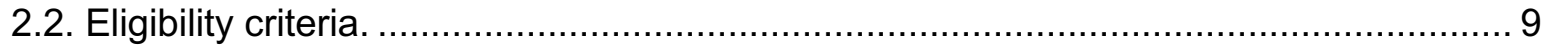

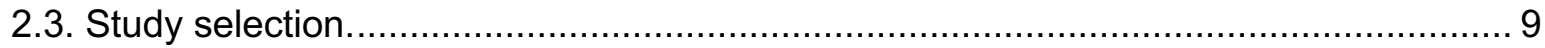

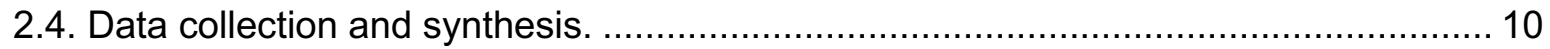

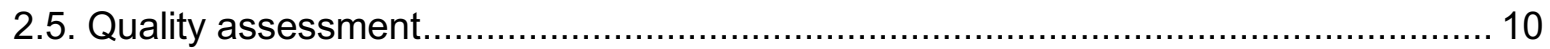

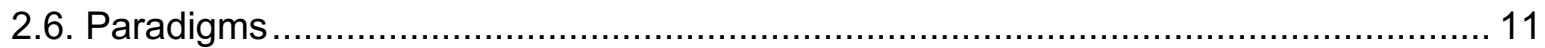

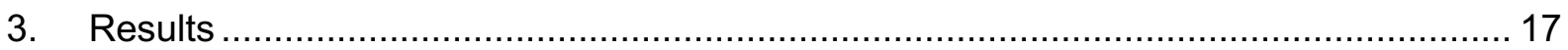

3.1. Study selection and overall quality assessment .............................................. 17

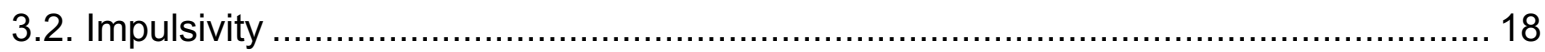

3.2.1. Choice impulsivity/Delay and probability discounting ..................................... 19

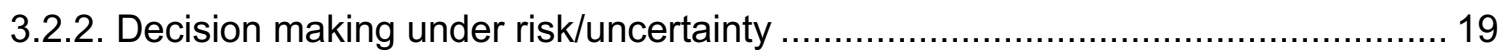

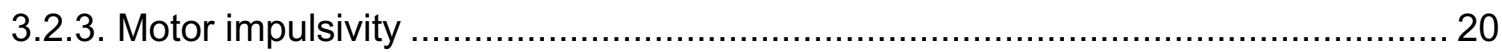

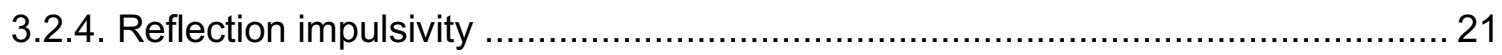

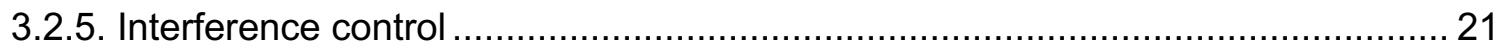

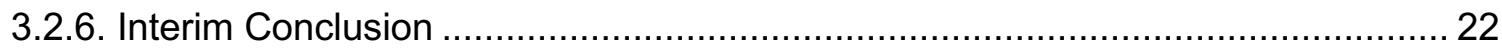

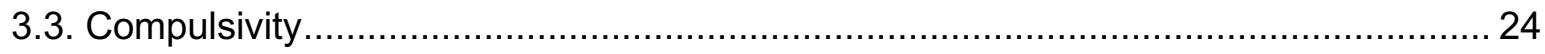

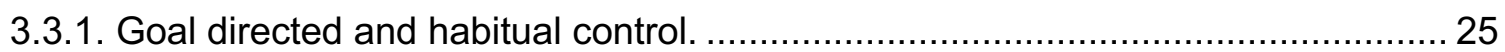

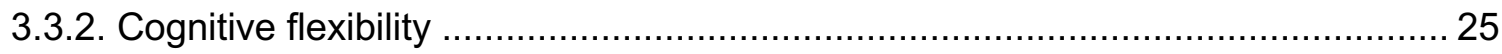

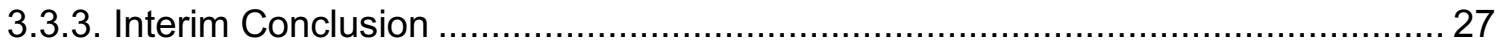

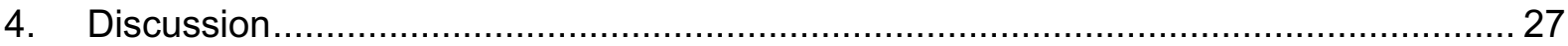

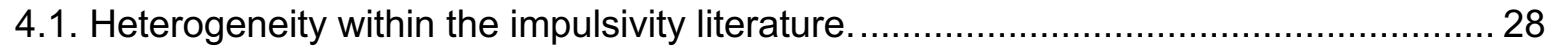

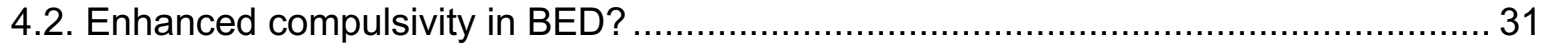




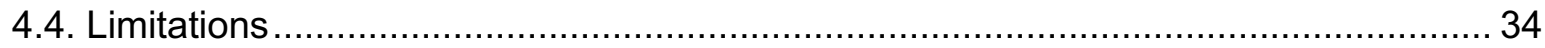

4.5. Conclusion and recommendations for future studies.......................................... 35

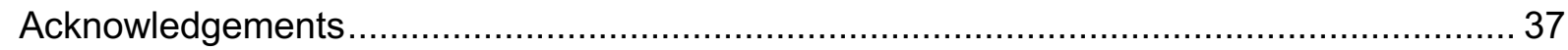

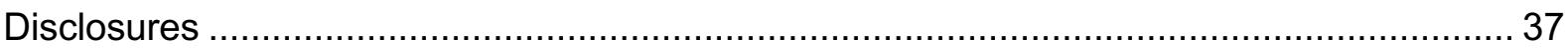

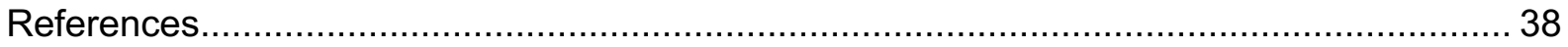

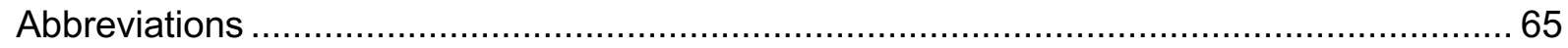

\section{Introduction}

Binge eating (BE), the consumption of large amounts of food associated with a subjective feeling of loss of control, is very common in the general population. It has an estimated prevalence of around 7\% (Brazil, Belgium) to up to 50\% (USA, Palestine) (Badrasawi and Zidan, 2019; de França et al., 2014; Lipson and Sonneville, 2017; Serra et al., 2020). BE occurs transdiagnostically in varying degrees of regularity across eating disorders as well as comorbidly in other psychiatric conditions (e.g. Boulanger et al., 2018; Braun et al., 2019). Binge Eating Disorder (BED), the most common eating disorder (Kessler et al., 2013), lies at the extreme end of the spectrum and is characterized by frequent, distressing binges (Box 1). It is associated with poor mental and physical health outcomes (Kessler et al., 2013; Thornton et al., 2017; Welch et al., 2016; Yanovski et al., 1993). Thus, patients are at elevated risk for a wide range of other psychiatric disorders (Welch et al., 2016) as well as obesity and associated conditions (Fabricatore and Wadden, 2006; Fairburn et al., 2000; Kessler et al., 2013; Tanofsky-Kraff et al., 2006; Udo and Grilo, 2018; Villarejo et al., 2012). BE as well as BED usually start in adolescence and early adulthood, which enhances the risk for chronicity. Hence, binge eating in the general population, and more categorically reflected in BED, represents a significant public health challenge. Psychological and pharmaceutical treatments 
are available, but more than one in five patients do not improve significantly after receiving specialized psychotherapy (McElroy et al., 2015). Pharmacological treatments, mostly prescribed off-label, appear to be similarly limited (Reas and Grilo, 2015), although lisdexamfetamine has shown promise in recent years (Heo and Duggan, 2017). In order to improve prevention and care, a more thorough understanding of the development and maintenance of $\mathrm{BE}$ is crucial.

The inability to resist the urge to overeat despite negative consequences is pivotal in BED. Patients repetitively engage in this maladaptive behavior against their explicit intent, suggesting that some imbalance of behavioral control is key. Impulsivity and compulsivity are prime candidates here. Impulsivity can be defined as "a predisposition toward rapid, unplanned reactions to internal or external stimuli with diminished regard to [their] negative consequences" (Fineberg et al., 2014). BED patients might be easily distracted from current goals by stimuli that promise reward, and appear to have trouble inhibiting their responses to such stimuli, including food stimuli. Similarly, compulsivity may well contribute to the development and maintenance of BED. It can be defined as the "performance of repetitive and functionally impairing overt or covert behavior without adaptive function, performed in a habitual or stereotyped fashion, either according to rigid rules or as a means of avoiding perceived negative consequences" (Fineberg et al., 2014). The hallmark of BED is such a behavior: repetitive overeating despite known negative consequences. Impulsivity and compulsivity partially overlap (Chamberlain et al., 2018; Gillan et al., 2016a), so that it is conceivable that both coexist in BED. Consistent with a role in the disorder, there is ample evidence of enhanced self-reported impulsivity - as measured by e.g. the Barratt Impulsiveness Scale (Patton et al., 1995) or the Urgency, Premeditation, Perseverance, Sensation Seeking, Positive Urgency, Impulsive Behavior Scale (Lynam et al., 2006; Whiteside and Lynam, 2001) in BED (Farstad et al., 2015; Kelly et al., 2014; Kollei et al., 2018; Lee et al., 2017; Lyu et al., 2018; Meule and Platte, 2015; Nasser et al., 2004; Oliva et al., 
2019; Racine et al., 2015, 2017; Schag et al., 2013; Voon et al., 2015c) (but see also e.g. Carriere et al., 2019). Reporting on self-reported compulsivity in BED is less abundant, perhaps owing to the fact that there are few instruments assessing compulsivity in transdiagnostically, i.e., outside of the context of obsessive compulsive disorder (OCD) (Hook et al., 2021). Instead, questionnaires are often diagnostic (yielding a binary outcome as to the presence of OCD) or assess both compulsions and obsessions in an OCD-specific way (Hook et al., 2021). Nonetheless, there is preliminary work showing an association between BED severity and binge eating related obsessions/compulsions as measured by the Yale-Brown obsessive compulsive scale modified for binge eating (Deal et al., 2015). In addition, there is evidence that individuals suffering from BED score higher on the Yale Food Addiction Scale (Burrows et al., 2017; Carter et al., 2019; Gearhardt et al., 2016, 2009). This can be interpreted as a sign of enhanced addictive-like or compulsive eating, although the concept of food addiction in itself is controversial (Fletcher and Kenny, 2018; Ziauddeen and Fletcher, 2013).

Such reports are extremely valuable when it comes to thinking about how BED patients might lose control of their eating behavior during binges. However, they do not capture the processes that lead to in-the-moment impulsive or compulsive actions. Such mechanistic insight is crucial in order to improve therapies aimed at preventing lapses of control. In this respect, research employing cognitive tasks has a number of advantages. First, tasks can manipulate impulsive and compulsive behavior and thus provide insights into mechanisms. Second, concurrent brain measures allow relating behavior to its neural substrates. Third, tasks can be used translationally, i.e. in both humans and animals. In animal models, tight control of confounders such as genetic and environmental differences, but also food availability and composition, is possible. Likewise, neurobiological substrates can be accessed more directly thanks to invasive methods (such as single cell recordings, microdialysis). The last decade has seen a rapid proliferation of neurocognitive/-behavioral research on impulsivity and compulsivity in BED - often inspired by addiction models (Everitt and Robbins, 2005; Smith and Robbins, 
2013) - in animals and humans. In this systematic review, we survey this work and critically appraise the progress that has been made. Specifically, we ask whether the literature consistently points towards enhanced behavioral impulsivity, compulsivity or both in BE. This would yield mechanistic insights into loss of control during binge eating episodes and help us identify promising neurocognitive markers of BED. This would yield mechanistic insights into loss of control during binge eating episodes and help us identify promising neurocognitive markers of BED. We consider studies comparing human subjects suffering from sub-clinical or clinical BED (but not other eating disorders) and healthy controls, as well as studies comparing normal and binge-like eating animals. Our review extends recent work on the same constructs in anorexia and bulimia nervosa (Howard et al., 2020). It complements other up-todate reviews (Cury et al., 2020) by including a wider range of tasks as well as animal and functional neuroimaging studies. Importantly, we take a translational perspective: we scrutinize the consistency of findings within translational levels (e.g., in human behavioral studies only), but we also compare and contrast findings across different translational levels. Thus, we note, for example, whether a behavioral finding in rodents holds up in humans, and whether neurofunctional findings have behavioral correlates. Moreover, we embed findings with clinical observations, highlight methodological issues, identify gaps in the literature, and provide recommendations for future investigations. 
Box 1. Definition of Binge Eating Disorder and its Assessment in Humans and Animals

BED in humans is clinically diagnosed when an individual reports frequent excessive food intake associated with a subjective feeling of loss of control and at least three of (1) eating much more rapidly than normal, (2) eating until feeling uncomfortably full, (3) eating large amounts of food when not feeling physically hungry, (4) eating alone because of feeling embarrassed by how much they are eating, and/or (5) feeling disgusted with themselves, depressed, or very guilty, at least once a week on average, for at least 3 months, without inappropriate compensatory behavior (American Psychiatric Association and Association, 2013). Note that although many patients with BED are obese, elevated BMI is not a diagnostic criterion and some patients are able to maintain a healthy weight.

Animal models of binge like eating behavior typically rely on intermittent access to (mostly palatable) food, in restriction-refeeding cycles (e.g. Oswald et al., 2011), via alternating access to standard chow and palatable food (e.g. Rossetti et al., 2014), or via intermittently granting access to palatable food in addition to standard chow (LeMon et al., 2019), under otherwise standardised conditions. All strategies lead to increased consumption of calories compared to normally fed animals in some, but not all, allowing to sort animals into binge eating prone (BEP) and binge eating resistant (BER) phenotypes.

\section{Methods}

This systematic review follows recommendations given in the Preferred Reporting Items for Systematic reviews and Meta-Analyses (PRISMA) statement (Liberati et al., 2009). 


\subsection{Information sources and search}

We searched the PubMed database for articles published between January $1^{\text {st }}, 2010$ and December $22^{\text {nd }}, 2020$ using the following search terms: "binge eating" and "response inhibition”, "delay discounting", "risk decision making", "decision making”, "motor impulsivity", "reflection impulsivity", "interference", "goal directed", "set shifting", and "cognitive flexibility", respectively. The definition of these search terms was informed by the work of Fineberg et al., (2014) and Stahl et al. (2014), who provide subdivisions of the (behavioral) compulsivity and/or impulsivity constructs along with typical operationalization. We additionally included other relevant articles that we had prior knowledge of.

\subsection{Eligibility criteria.}

We considered studies in English that reported comparisons between humans or animals with and without binge eating symptoms (full or subsyndromal BED), i.e., case-control studies, on task-based measures of impulsivity and compulsivity. Most of the measures we recognized as operationalization of subdomains of impulsivity and compulsivity were mentioned as such in Fineberg et al., (2014) and Stahl et al. (2014). In addition, we also included measures that were explicitly mentioned to be used to assess the construct in question in the original studies (e.g. the N-back task with lures, which was used to measure interference control in Svaldi et al. (2014b)). We did not include studies on samples with eating disorders other than BED.

\subsection{Study selection.}

We downloaded the full citations of all articles returned by our search and collected them using Mendeley Desktop, version 1.19.4. We used Mendeley's built-in utility to remove duplicates that had not been removed automatically on import. We then scanned titles and abstracts of all remaining records and excluded those that did not match our eligibility criteria. Finally, we scanned the full-text articles associated with the remaining records to ensure that eligibility 
criteria were indeed met. We identified sets of papers in which the same data was re-published and included only one of each in our tables and qualitative summary.

\subsection{Data collection and synthesis.}

For each eligible study in humans, we extracted sample size (per group), mean and standard deviation (or other reported summary statistics) of age and BMI, as well as gender composition of the sample (female only, male only, mixed), paradigms employed and main outcomes. In one case, univariate statistics were not reported; we obtained them by contacting the authors (Kollei et al., 2018). For each eligible study in animals, we extracted sample size (per group), species, sex (female only, male only, mixed), paradigm, and main outcomes. We simplified results so that they are shown in our tables and figures as comparative symbols $(<,>,=)$ depending on the direction and significance of the observed effect.

\subsection{Quality assessment}

For each study in humans, MW performed quality assessment according to the NewcastleOttawa scale (NOS) for quality assessment adapted for cross sectional studies (Wells et al., 2021). The scale assesses case definition, representativeness of the cases, selection of controls, definition of controls, comparability of cases and controls, ascertainment of exposure, equality of ascertainment for cases and controls, and non-response rate. The maximum number of points ("stars") a study can achieve is eight, where each category is represented by one star with the exception of comparability, where two stars are possible. We are unaware of scales specifically developed to assess case-control studies in animals and have therefore not performed quality control for these studies. 


\subsection{Paradigms}

Many different paradigms have been designed to study different aspects of impulsivity and compulsivity. Here, we provide brief descriptions of those used in studies identified in our literature search.

Delay and probability discounting. Delay and probability discounting is a facet of impulsivity (Fineberg et al., 2014; Stahl et al., 2014). In the monetary choice questionnaire (Kirby et al., 1999) participants make 27 choices between smaller, immediate rewards and larger, delayed rewards. The choices are fixed. From the responses, a discount parameter $k$ is computed, describing the hyperbolic discount rate (the larger $k$, the steeper the discounting). In the monetary temporal discounting task (Rubia et al., 2009), participants choose between smaller, immediate rewards and larger, delayed rewards by button press. There are three delays and 20 trials per delay. The immediate reward is adjusted based on the participants' previous choices, which allows for the calculation of indifference values as well as the discount parameter $k$ (s.a.). In the delayed discounting task (Robles and Vargas, 2007), participants make 240 choice trials between 30 hypothetical cash rewards, with 8 delay magnitudes. Outcome measures are the discount parameter $k$ or area under the curve. In the delay and probability discounting tasks used by (Manwaring et al., 2011), participants make choices between different amounts of natural and monetary rewards (money, a snack food selected by the participant, a preferred sedentary activity, and massage time). In the delay discounting task, they are told that they could have one of the rewards immediately, the other with a delay (one of five); in the probability discounting task, they are told that they could have one of the rewards for sure, the other with a certain probability (one of five). The amounts of the immediate rewards are adjusted over six trials per delay/probability in order to estimate indifference points or subjective values.

Risky decision making. Risky or disadvantageous decision-making is a facet of impulsivity (Fineberg et al., 2014). In the lowa Gambling Task (Bechara et al., 1994), 
participants make choices between four decks of cards. Turning decks A and B (disadvantageous decks) yields high wins but also penalties, such that participants incur a net loss over time; turning decks $C$ and D (advantageous decks) yields smaller wins but also penalties, such that participants achieve net wins over time. $A$ and $C$ have more frequent, smaller penalties, whereas B and D have less frequent, larger penalties. Standard outcome measures are the number of advantageous decks ( $C$ and $D)$ chosen over all trials or blocks of trials to reflect learning. Fewer advantageous choices can be interpreted as more risky behavior. In the Cambridge Gambling Task (Rogers et al., 1999), participants are instructed that at each trial, one of ten red or blue (different ratios) boxes shown on a screen contains a yellow token. They can choose to bet one of five amounts (fixed proportions of their current winnings) on the color of the box containing the token. The betting amounts are presented successively in ascending or descending order, depending on condition. Typical outcome measures are reaction time, quality of decision making (how often the more likely color is chosen) and risk-adjustment (the rate at which participants adjust the betting amount to more favorable ratios of blue and red boxes). In the Balloon Analogue Risk Task (BART) (Lejuez et al., 2002), participants can win money by using a pump to inflate images of 30 balloons. The larger the balloon when they cash out, the larger their winnings; however, the balloons have (different) break-points, and when they explode, participants earn no money. The primary outcome measure is the adjusted average number of pumps on unexploded balloons. Higher numbers suggest more risky behavior. In the Risky Jar Task (Voon et al., 2015c), participants choose between a jar containing only red balls and a jar containing variable proportions (4 different proportions) of red and blue balls. One ball is randomly chosen from the selected jar; if it is read, participants gain the amount of money specified for each jar. For the risky jar, one of 4 different amounts is displayed. For each prospect (proportion-amount combination of the risky jar), the value of the certain jar is adjusted in a stepwise manner to find the certainty equivalent. The main outcome measure is the probability weight inferred from the certainty equivalents. In the Game of Dice Task (Brand et al., 2005), participants throw a single die 
eighteen times and place bets on the outcome. They can bet on a single number, or either of two, three, or four numbers. The win/loss probabilities of each option are made explicit. The lower the win probability, the higher the potential gain or loss. The main outcome measure is the number of risky or disadvantageous decisions, i.e. one or two numbers (win probability $<50 \%$ ). In the original Door Opening Task (Daugherty and Quay, 1991), participants can open between one and ten doors at every trial to see happy faces (and gain a point) or sad faces (and loose a point). The win probability decreases by $10 \%$ per door opened, such that later doors tend to confer more losses then wins (i.e., become riskier). The participants can stop the trial at any time and collect their earnings. The main outcome measure is the number of doors opened. (Preuss et al., 2019) adapted the task to include pictures of low-caloric foods with the happy faces and pictures of high-caloric foods with the sad faces.

Motor impulsivity. Motor impulsivity or inhibition is a facet of impulsivity (Fineberg et al., 2014; Stahl et al., 2014). In the Stop Signal Reaction Time task (Logan et al., 1984; Verbruggen and Logan, 2008a), participants respond as fast as possible to particular stimuli, unless they see a stop signal (a tone or other stimulus), in which case they must withhold their response. The main outcome measures are stop-signal reaction times, as well as commission errors (failing to withhold the response) and omission errors (failing to show the response). In the Go-NoGo task (e.g., Verbruggen and Logan, 2008b), participants respond as fast as possible when presented with so-called go stimuli and withhold responses when presented with no-go stimuli. Typical outcome measures are commission errors (failing to withhold a response) and omission errors (failing to show a response). The premature response task (Voon et al., 2014a) is a task modeled on the 5-choice-serial-reaction-time task used in rodents. When shown four boxes on a touchscreen, participants are told to press and hold a key until they see a green target circle in one of the boxes, upon which they must release the key and touch the target box as quickly as possible to gain money. The main outcome measure is premature release of the key prior to target onset. 
Reflection impulsivity. Limited reflection before making a decision is a facet of impulsivity (Fineberg et al., 2014). In the information sampling task (Clark et al., 2006), participants are faced with 25 grey boxes, each of which contains one of two colors. To win money, they must correctly guess, after opening as many boxes as they wish, which color the majority of the boxes hide; incorrect responses result in losses. In one condition, the reward is fixed, in the other, the available reward decreases with boxes opened. Typical outcome measures are correct and incorrect choices, reaction times, and the mean number of boxes opened per trial.

Interference control. Limited capacity to control the influence of interfering stimuli (proactive, response, and stimulus interference) is a facet of impulsivity (Stahl et al., 2014). In the recent probes task (e.g. Svaldi et al., 2014b), participants must, at each trial, memorize a set of stimuli and decide whether a probe was part of the set after a brief retention interval. Sometimes, the probe was not contained in the current set but in the one from the immediately preceding one, such that performance is subject to interference. Typical outcome measures are the difference in reaction times to recent vs non-recent non-matching probes as well as accuracy. In the n-back task with lures (e.g., Svaldi et al., 2014b), participants are successively presented with a series of stimuli. After a while, they are presented with a probe and asked whether it had been shown $\mathrm{n}$ trials earlier. Lures are probes which had been presented $n+1$ or $n-1$ trials earlier. Typical outcome measures are accuracy and reaction time. In the anti-saccade task (e.g., Schag et al., 2013), participants are presented with stimuli (disorder-relevant or irrelevant) on one side of a screen and told to avert their gaze as quickly as they can. Outcome measures are directional errors in the first and second saccade. In the (Eriksen) Flanker task (Eriksen and Eriksen, 1974), participants respond to a stimulus at the center of a screen with one of two instructed actions (e.g., press left or press right). The target stimuli are flanked by either congruent stimuli (i.e., stimuli which require the same response), incongruent stimuli (i.e., stimuli which require a different response), or neutral stimuli (which 
require no response). Typical outcome measures are reaction times and accuracy. In the original Stroop task (MacLeod, 1991; Stroop, 1935), participants are asked to read aloud color words that are either congruently or incongruently colored (e.g. the word "green" written in green or red). The main outcome measure is the difference in reaction time between congruent and incongruent conditions as well as accuracy. The task has been adapted for a food context. Here, participants are asked to name the color food and non-food words are written in. The main outcome measures are again reaction time and accuracy (e.g., Preuss et al., 2019).

Goal-directed control. Relative insensitivity to outcomes or goals is a facet of compulsivity (Fineberg et al., 2014). In devaluation sensitivity paradigms, animals learn to emit a specific response to obtain a reward (e.g. sucrose), which is later devalued (e.g. through ad libitum access). The task assesses continued responses after devaluation (e.g. number of lever presses in a fixed time period after devaluation). In the Two-step task (Daw et al., 2011), participants try to win money by making two binary choices between abstract stimuli at each trial. The first-stage choice probabilistically leads to one of two possible second stage choice options, such that there is a rare and a common transition. The second-stage choice is rewarded with different probabilities depending on the stimulus chosen. To encourage ongoing learning, the win probabilities of the second-stage options continually change based on gaussian random walks. The main behavioral outcome measure is the interaction effect between second-stage feedback and transition type (rare or common) on the probability of sticking with the same first-stage choice: a large interaction effect indicates goal-directed or model-based control. Computational modeling yields further outcome measures such as a weighting parameter $w$ which quantifies the contribution of goal-directed or model-based control.

Contingency related cognitive flexibility. Relative behavioral inflexibility in response to changing reward contingencies is a facet of compulsivity (Fineberg et al., 2014). Aversive conditioning is a standard animal paradigm where animals are trained to associate a 
(pleasant) behavior, e.g. eating sucrose, with unpleasant outcomes such as footshocks. The latency of learning can be interpreted as perseveration. In probabilistic reversal learning tasks (e.g., Cools et al., 2002), participants learn to choose one stimulus over another based its probability of yielding positive feedback (typically monetary). After a while, the reward contingencies reverse: the participants must relearn the stimuli's values and flexibly adjust their responses. Several different versions exist with different numbers of reversals and where the time between reversals is either fixed or based on a learning criterion.

Set-shifting. Relative behavioral or attentional inflexibility in response to changing task demands is a facet of compulsivity (Fineberg et al., 2014). In the "Behavioral Assessment of the Dysexecutive Syndrome” (BADS) rule shift task (Wilson et al., 1996), participants are successively presented with 21 playing cards. They are instructed to respond "yes" to red cards and "no" to black cards in the first part of the task; and to respond "yes" if the current card has the same color as the previous one and "no" otherwise in the second part, which requires flexible adaptation. Reaction time and accuracy are the main outcome measures. In the intra-extradimensional set shifting task (Downes et al., 1989), participants are asked to choose, at every trial, between two patterns of stimuli which vary along two dimensions (e.g. color and shape). To make the correct choice, participants must work out the underlying rule, which changes several times over the course of the task. The task covers contingency reversals, intradimensional shifts (where exemplars, but not the rule-relevant dimension change), and extradimensional shifts (where exemplars and the rule-relevant dimension change) in subsequent blocks that can be reached after a learning criterion is reached. The main outcome measures are accuracy, reaction times, and number of blocks and trials completed. In the Penn conditional exclusion task (Kurtz et al., 2004), participants choose, at each trial, one of four figures that is different from the other three. The correct response is based on one of three rules, which the participant must work out. The main outcome measures are total number of categories (rules) achieved, errors, trials to first category, and total number 
of trials. In the Trail-Making Task Part B (TMT-B) (Reitan, 1958, 1955), participants must draw a line connecting 25 circles marked with numbers between 1 and 13 and letters between A and $L$, as quickly as possible, in ascending order, alternating between numbers and letters (i.e., 1-A-2-B etc.). The main outcome is the latency by which participants complete the test. In the Wisconsin card sorting task (Berg, 1948), participants are presented with 4 sample cards and one probe card and are asked to match the probe to one of the sample cards. The sample cards differ in terms of the color, shape, or number of stimuli on them. Participants must work out the current matching rule based on trial-by-trial feedback. After a fixed number of correct responses, the rule shifts and participants must adapt their strategy. Typical outcome measures include rules achieved, trials, errors, and perseverative errors.

\section{Results}

\subsection{Study selection and overall quality assessment}

We identified a total of 559 relevant records, 57 of which we ultimately included (for details of the selection process, see Figure 1). At the final stage of selection, we identified two pairs of articles in which data was re-published (Manasse et al., 2015a, 2015b; Schag et al., 2019, 2013); we included only one of each in our synthesis.

The majority of studies had adequate quality as assessed by the NOS score ( 5 or 6 stars). No study achieved more than 6 stars. Very few studies had explicitly representative samples and none reported non-response rates for cases and controls separately. Studies that achieved under 5 stars mostly did so because of incomplete or unclear reporting of methods or failure to control for important variables such as BMI or age. For the number of stars achieved by each study, see Tables 1 through 7. 


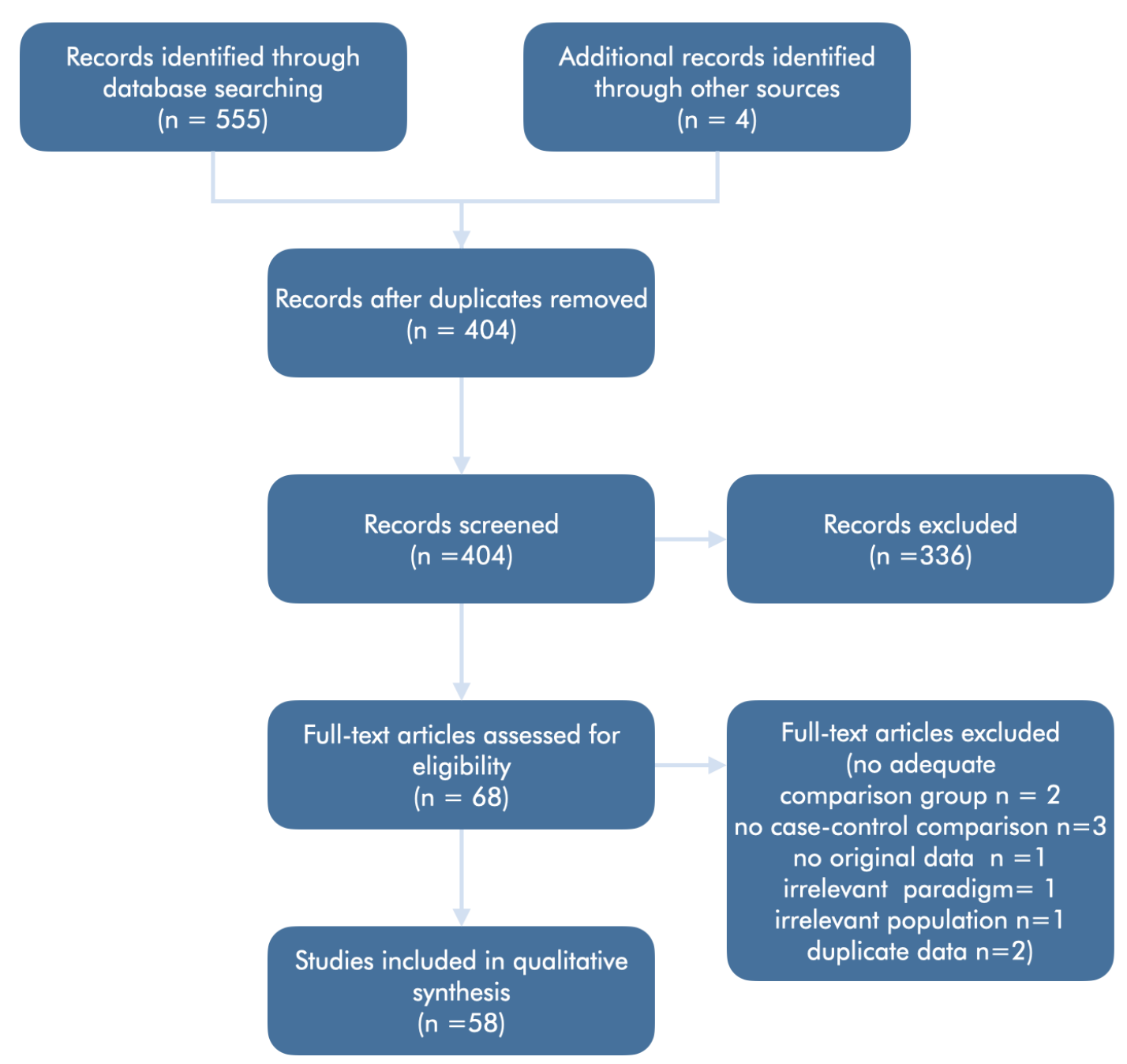

Figure 1. Study selection process.

\subsection{Impulsivity}

A variety of cognitive tasks have been designed to capture different but interrelated aspects of the impulsivity construct: choice impulsivity (e.g. delay discounting tasks), risky decision making (e.g. gambling tasks), motor impulsivity (e.g. Stop-Signal / Go-NoGo tasks), and reflection impulsivity, i.e. the tendency to gather and evaluate information prior to decisionmaking (Clark et al., 2006) (e.g. the Cambridge Information Sampling task), as well as susceptibility to interference by stimuli prior to or during task performance (e.g. recent probes 
task and Stroop task, respectively), and during response selection (e.g. Flanker task) (Fineberg et al., 2014; Stahl et al., 2014). All of these facets of impulsivity have been investigated in relation to binge eating (both subclinical and full-blown BED). Where available, we synthesize evidence from animal studies first and compare it with evidence from human subjects. Where possible, we also report on psychophysiological correlates.

3.2.1. Choice impulsivity/Delay and probability discounting. As shown in Figure 2.A., there is evidence of steeper delay discounting, i.e., a preference for smaller, earlier rewards, in binge eating prone (BEP) rats (Cano et al., 2016; Vickers et al., 2017) (although see Moore et al., 2018). Consistent with this, the literature also predominantly points towards enhanced discounting in human BED subjects compared to normal weight (NW) controls (Davis et al., 2010; Mole et al., 2015; Steward et al., 2017)(although see Bartholdy et al., 2017a; Yan et al., 2018). However, it is less clear whether this is driven by loss of control (LOC) eating or weight status. Indeed, while some studies do find deficits compared with weight matched controls (Manasse et al., 2015b; Manwaring et al., 2011), others do not (Blume et al., 2018; Davis et al., 2010; Mole et al., 2015), casting doubt on the specificity of the effect. For study characteristics, see Table 1.

3.2.2. Decision making under risk/uncertainty. Decision making under risk/uncertainty has not yet been investigated in animal models of BED. In humans, investigations are ample, but the results are inconclusive (Figure 2.B). On the lowa Gambling Task and equivalent paradigms, some studies find enhanced maladaptive decision making under uncertainty in BED compared to NW (Aloi et al., 2020, 2015; Danner et al., 2013, 2012; Davis et al., 2010) and overweight (OW) controls (Córdova et al., 2017; Muller et al., 2014). Others find no such differences comparing BED to NW (Dingemans et al., 2019; Grant and Chamberlain, 2019; Kittel et al., 2017; Kollei et al., 2018) or OW controls (Aloi et al., 2020; Blume et al., 2018; Danner et al., 2012; Davis et al., 2010; Grant and Chamberlain, 2019; Kittel et al., 2017). In studies employing less common paradigms, enhanced risk taking was observed in some 19 
samples (Svaldi et al., 2010; Voon et al., 2015c) but not others (Manasse et al., 2015b; Preuss et al., 2019; Wu et al., 2013). Thus, it remains uncertain what role risky decision-making might play in BED. For study characteristics, see Table 2.

3.2.3. Motor impulsivity. To our knowledge, no animal studies have yet directly compared rodents with normal and binge-like feeding patterns on motor impulsivity. However, converging evidence suggests that "waiting" impulsivity (the ability to withhold a response) predicts binge size in rats on a BE protocol (Anastasio et al., 2019; Velázquez-Sánchez et al., 2014). In humans, no group differences in "waiting" impulsivity were observed between BED subjects and OW or NW controls in the sole study that assessed it (Voon et al., 2014b). Motor impulsivity is more frequently assessed as "stopping" impulsivity (the ability to abort a response) in humans, using the Go-NoGo or stop signal reaction time tasks (SSRTT). On these and equivalent tasks, many studies report altered motor impulsivity associated with binge eating (Córdova et al., 2017; Grant and Chamberlain, 2019; Hege et al., 2015; Lyu et al., 2017; Manasse et al., 2016; Mobbs et al., 2011; Mole et al., 2015; Preuss et al., 2019; Svaldi et al., 2014a). However, across studies, these alterations are often seen on different metrics of the same task, between different weight status groups, or in food/non-food versions of the tasks (Figure 2.C), so that the effects are not strictly comparable. In addition, an almost equal number of studies reports no differences (Antunes et al., 2020; Bartholdy et al., 2019, 2017b; Blume et al., 2018; Kollei et al., 2018; Loeber et al., 2018; Oliva et al., 2019; Wu et al., 2013). Neuroimaging studies on the Go-NoGo task indicate decreased activation of the middle frontal gyrus/dorsolateral PFC during NoGo trials in BED (Hege et al., 2015; Oliva et al., 2019). This was suggested to reflect difficulty recruiting necessary control resources, but was only related to behavior in one investigation (Hege et al., 2015). On the SSRT, BE has been associated with altered activity during stop trials in the middle frontal gyrus (Oliva et al., 2019), but this finding could not be related to behavior. Thus, the animal literature suggests a relationship between motor impulsivity and binge eating, but inconsistencies abound in the human 
behavioral and psychophysiological data, precluding straightforward interpretation. For study characteristics, see Table 3.

3.2.4. Reflection impulsivity. Compared to other aspects of impulsivity, interest in reflection impulsivity in BE has been scant. Only one study has looked at it so far (Figure 2.D). On an information sampling task, human BED subjects did not differ from NW controls and outperformed OW controls (Mole et al., 2015). Preliminarily, this suggests no specific impairment associated with LOC eating in this domain. For study characteristics, see Table 4.

3.2.5. Interference control. Like reflection impulsivity, interference control has not yet been investigated in animal studies on BED. In humans, all of its three subdomains - stimulus, response, and proactive interference - have been studied, but the results are inconclusive (Figure 2.E). Group differences in stimulus interference, as assessed using the Stroop task or equivalent paradigms, have been documented (Kittel et al., 2017; Manasse et al., 2015b), but most studies report no differences between BED and NW (Balodis et al., 2013; Lee et al., 2017) or OW controls (Balodis et al., 2013; Dingemans et al., 2019; Duchesne et al., 2010; Eneva et al., 2017; Galioto et al., 2012; Preuss et al., 2019). This is irrespective of whether a traditional or a food version was used. Neuroimaging data suggests reduced activity in ventral parts of the PFC and the insula during incongruent Stroop trials (Balodis et al., 2013), and enhanced activation of the ventral striatum and postcentral gyrus in response to food stimuli in the Stroop Task (Lee et al., 2017) in BED. However, since these neuronal differences were not related to behavior, interpretations of these findings as reflecting diminished inhibitory control or enhanced bottom-up processing are speculative. The few studies on response interference, measured using the Flanker task, yield conflicting results regarding performance differences between BED subjects and controls (Eneva et al., 2017; Lyu et al., 2018). Likewise, there is evidence of reduced as well as intact performance, respectively, on tasks assessing distractibility or proactive interference in BED. Thus, patients have more difficulty than OW controls on the N-Back with lures and the anti-saccade task (Schag et al., 2013; Svaldi et al., 
2014b), but perform equally well on a recent probes task (Svaldi et al., 2014b). In sum, the literature on interference control is inconclusive as to a potential deficit in BED either. For study characteristics, see Table 5.

3.2.6. Interim Conclusion. Overall, we note that the literature on impulsivity in BED is extremely heterogeneous. There is little continuity across translational levels (from animal to human and from behavior to neural underpinnings). In addition, behavioral results are inconsistent across and within subconstructs of impulsivity. The sample composition in terms of age and gender, as well as the use of food vs non-food stimuli does not seem to have consistent effects on whether enhanced impulsivity emerges in BE samples or not. Similarly, differences do not emerge exclusively in comparison with OW or NW controls, respectively, which would point to a BMI confound. Given such indeterminate evidence, it is difficult to draw firm conclusions on the processes underlying impulsive failures of behavioral control in BED. 


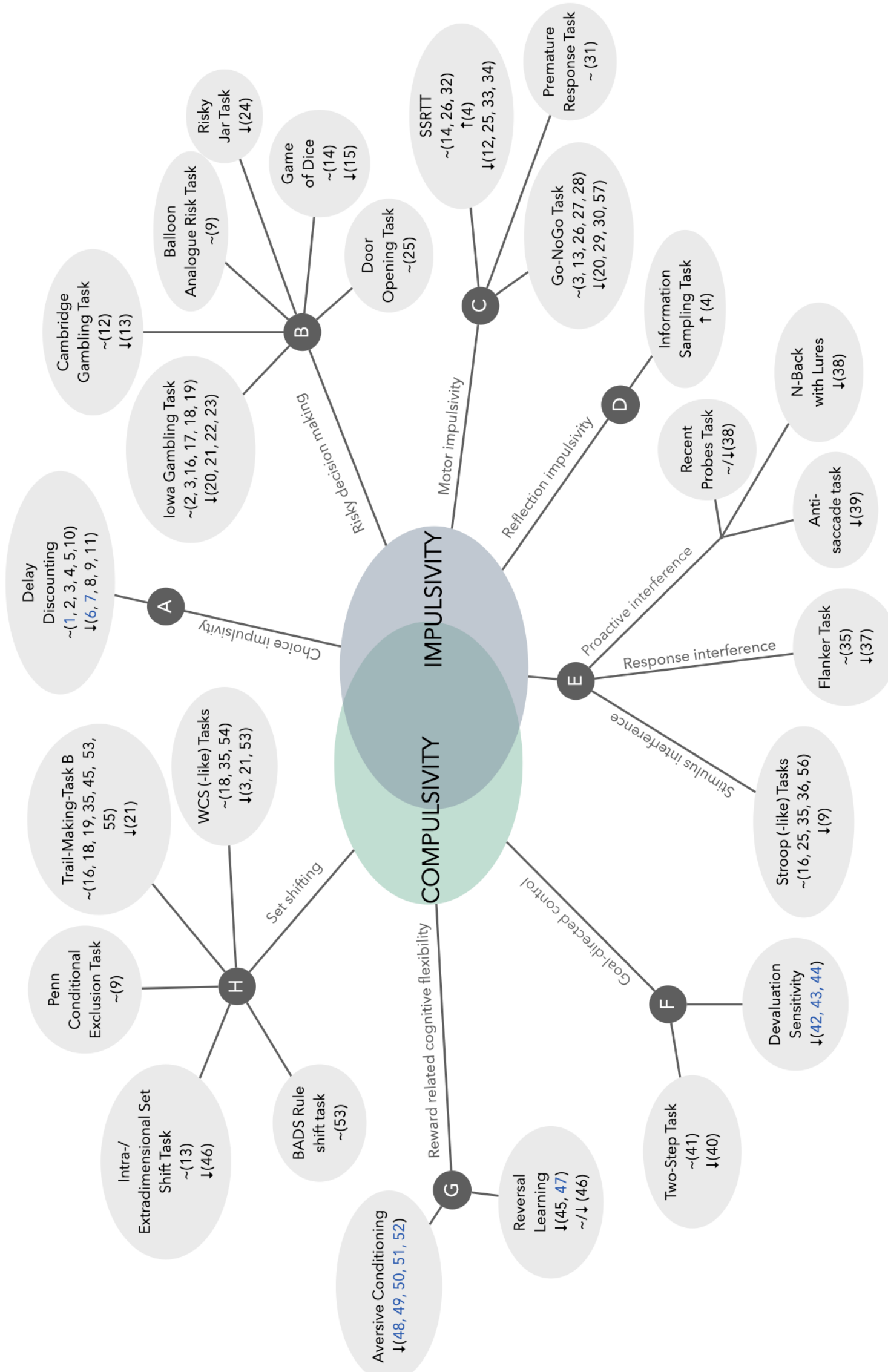


Figure 2. Overview of studies.

99, Animal study; $\uparrow$, Relatively improved performance in Binge Eating or Binge Eating Disorder (BED); $\downarrow$, Relatively impaired performance in BE(D); , No significant difference; / $\downarrow$, Partial effect. Comparisons are between $\mathrm{BE}(\mathrm{D})$ and normal- or overweight/obese controls as reported in the respective studies. Where both comparisons were made, we show the comparison between $\mathrm{BE}(\mathrm{D})$ and overweight/obese participants. SSRT, Stop-Signal-ReactionTime-Task; BADS, behavioral assessment of the dysexecutive syndrome; WCS, Wisconsin Card Sorting. 1 Moore, Blasio et al. (2018), 2 Davis, Patte et al. (2010), 3 Blume, Schmidt et al. (2019), 4 Mole, Irvine et al. (2015), 5 Yan, Zhang et al. (2018), 6 Vickers, Goddard et al. (2017), 7 Moore, Blasio et al. (2018), 8 Manwaring, Green et al. (2011), 9 Manasse, Forman et al. (2015), 10 Bartholdy, Rennalls et al. (2017a), 11 Steward, Mestre-Bach et al. (2017), 12 Grant \& Chamberlain (2019), 13 Kollei, Rustemeier et al. (2018), 14 Wu, Giel et al. (2013), 15 Svaldi, Brand et al. (2010), 16 Kittel, Schmidt et al. (2017), 17 Danner, Ouwehand et al. (2012), 18 Dingemans, Vanhaelen et al. (2019), 19 Aloi, Rania et al. (2020), 20 Cordova, Schiavon et al. (2017), 21 Aloi, Rania et al. (2015), 22 Müller, Brandl et al. (2014), 23 Danner, Evers et al. (2013), 24 Voon, Morris et al. (2014), 25 Preuss, Leister et al. (2019), 26 Oliva, Morys et al. (2019), 27 Antunes, Elkfury et al. (2020), 28 Loeber, Rustemeier et al. (2018), 29 Hege, Stingl et al. (2015), 30 Lyu, Zheng et al. (2017), 31 Voon, Irvine et al. (2014), 32 Bartholdy, Rennalls et al. (2017b), 33 Svaldi, Naumann et al. (2014), 34 Manasse, Goldstein et al. (2016), 35 Eneva, Arlt et al. (2017), 36 Lee, Namkoong et al. (2017), 37 Lyu, Zheng et al. (2018), 38 Svaldi, Schmitz et al. (2014), 39 Schag, Teufel et al. (2013), 40 Voon, Derbyshire et al. (2015), 41 Voon, Joutsa et al. (2020), 42 LeMon, Sisk et al. (2019), 43 Furlong, Jayaweera et al. (2014), 44 Parkes, Furlong et al. (2017), 45 Reiter, Heinze et al. (2017), 46 Banca, Harrison et al. (2016), 47 Chawla, Cordner et al. (2017), 48 Rossetti, Spena et al. (2013), 49 Moshe, Bekker et al. (2017), 50 Oswald, Murdaugh et al. (2011), 51 Velázquez-Sánchez, Santos et al. (2015), 52 Heal, Goddard et al. (2016), 53 Duchesne, Mattos et al. (2010), 54 Kelly, Bulik et al. (2013), 55 Galioto, Spitznagel et al. (2012), 56 Balodis, Molina et al. (2013), 57 Mobbs, Iglesias et al. (2011).

\subsection{Compulsivity}

The wealth of studies on compulsive behavior in BED falls far behind impulsivity-centered investigations. This is perhaps not surprising because some of its features are difficult to produce in a laboratory setting. Thus, habits are notoriously difficult to induce in humans (de Wit et al., 2018) - even more so if they are to withstand punishment. Likewise, we are unaware of neurocognitive tasks that probe stereotypies or the anxiolytic effect of compulsive behavior in BE. Nonetheless, a range of tasks has been employed to assess central aspects of compulsivity: the balance of goal-directed and habitual control (e.g., two step decision task), reward related cognitive flexibility (e.g., probabilistic reversal learning task), and task set 
related cognitive flexibility (e.g. Wisconsin Card Sorting Task). Where available, we synthesize evidence from animal studies first and compare it with evidence from human subjects.

3.3.1. Goal directed and habitual control. Goal-directed control is the ability to plan, carry out, and adjust actions in accordance with current goals, as opposed to following previously learned stimulus-response patterns (habitual control). In animal studies, this is typically assessed using devaluation protocols. There is converging evidence that binge eating behavior in rats is associated with reduced sensitivity to devaluation, such that the animals continue to respond to obtain food despite devaluation (Figure 2.F) (Furlong et al., 2014; LeMon et al., 2019; Parkes et al., 2017). Crucially, this seems to be specific to instrumental behavior and not due to altered consummatory preference (LeMon et al., 2019; Parkes et al., 2017). This suggests that the animals fail to act in accordance with their goals but driven by habit. In humans, habitual control in BED has received only little attention so far. One group reports relatively greater reliance on habitual rather than goal directed behavioral control on the two-step decision-making task (Daw et al., 2011) in BED subjects, compared to both NW and OW controls (Figure 2.J) (Voon et al., 2015b). This effect was evident both at the level of choice data and supported by computational modelling. It could not be replicated in a subsequent study (Voon et al., 2020). However, it should be noted that this latter study had a very small BED sample $(\mathrm{N}=7)$. Both studies report enhanced, feedback-independent choice perseveration (Voon et al., 2020, 2015a). For study characteristics, see Table 6.

3.3.2. Cognitive flexibility. Cognitive flexibility tasks require agents to adapt their responses to changing environments. Reward or contingency related cognitive flexibility, i.e., the ability to adjust to changing reward values, seems to be impaired in BE (Figure 2.G). There is solid evidence that binge eating is associated with reduced sensitivity to aversive conditioning in rodents (Heal et al., 2016; Moshe et al., 2017; Oswald et al., 2011; Rossetti et al., 2014; Velázquez-Sánchez et al., 2015). This effect does not seem to be specific to immediate, external aversive outcomes (such as footshocks) but also occurs when the aversive outcome 
is delayed and gastrointestinal (lactose "poisoning") (Moshe et al., 2017). In translational terms, this is important because this type of outcome more closely resembles the physical and psychological discomfort humans experience after binges. Consistently, binge eating rats have been shown to have trouble relearning changing reward contingencies in a reversal learning task, where they perseverated on a previously rewarding option more than did controls (Chawla et al., 2017). Likewise, human subjects with BED have also shown worse reversal learning performance than weight matched controls (Reiter et al., 2017). However, interestingly, this seemed to be driven by maladaptively enhanced switching between options rather than perseveration. This is suggestive of an imbalance between exploration and exploitation opposite to the perseveration (overexploitation) seen in rats. Supporting this interpretation, the authors also performed computational modelling, which yielded a higher choice stochasticity - indicative of greater exploration behavior - in the BED group, and found reduced activation of the right anterior insula/vIPFC during explorative trials. Partially convergent, another research group found a similar tendency to switch more between options in BED patients than NW controls in a one-reversal version of the task, although they observed no straightforward performance differences (Banca et al., 2016). Yet another study found that BED have a greater tendency to explore options than OW controls on a different task (Morris et al., 2016). This suggests that BED may be characterized by enhanced but maladaptive exploration that hinders cognitive flexibility. However, the above findings are complicated by differential observations in different weight-status groups and motivational contexts and should be interpreted carefully.

The picture is more muddled in tasks assessing set related cognitive flexibility or set-shifting, where agents have to switch between goals or shift their attention (Figure 2.H). Regardless of the specific tasks used, some research groups find differences in performance between BED subjects and NW (Aloi et al., 2020, 2015; Banca et al., 2016) or OW (Duchesne et al., 2010; Svaldi et al., 2010) controls, respectively. Others report no such differences compared to 
either NW (Dingemans et al., 2019; Eneva et al., 2017; Kelly et al., 2013; Kittel et al., 2017; Kollei et al., 2018; Reiter et al., 2017) or OW controls (Banca et al., 2016; Blume et al., 2018; Eneva et al., 2017; Galioto et al., 2012; Kittel et al., 2017; Kollei et al., 2018; Manasse et al., 2015b). Thus, whether or not set-shifting difficulties play a role in BED remains an open question. For study characteristics, see Table 7.

3.3.3. Interim Conclusion. Compared to what we saw in the impulsivity literature, the evidence on compulsivity in BED is relatively consistent regarding some subdomains (Figure 2.H-J). Binge eating associated alterations in reward related cognitive flexibility emerge across translational levels, i.e. in rodent studies as well as human behavioral and neurofunctional studies, as do alterations of goal-directed and/or habitual control. In contrast, the literature on set shifting is very heterogeneous, and does not exhibit patterns that would point to differences between samples or stimulus material as a source of this variability. Thus, the evidence on compulsive behavior in BED primarily points towards enhanced reward- and punishmentrelated compulsivity (disrupted reward-related cognitive flexibility and goal-directed behavioral control). However, we note that far fewer studies have investigated aspects of compulsivity than impulsivity, and that results remain to be replicated.

\section{Discussion}

Although there is solid evidence of enhanced self-reported impulsivity in BED, the surveyed literature indicates that this could not be shown consistently using behavioral tasks. We found little continuity across translational levels. Comparable studies yielded conflicting results in nearly all subconstructs considered. By contrast, we found that the more brittle evidence of self-reported compulsivity in BED tended to be at least partially reflected in behavioral findings, in both humans and animal models of the disorder. Thus, rodent and human studies 
convergently show relatively impaired reward related cognitive flexibility and enhanced reliance on habitual control.

\subsection{Heterogeneity within the impulsivity literature.}

The fact that we did not find consistent evidence of enhanced impulsive behavior in our review, in spite of self-report evidence to the contrary, is not necessarily surprising. Several studies have shown that self-report and behavioral measures of impulsivity do not correlate well and might indeed measure different constructs (Cyders and Coskunpinar, 2011; Reynolds et al., 2006; Stahl et al., 2014). By contrast, the heterogeneity of findings within the behavioral literature itself is remarkable and unexpected. It severely curtails the interpretability of individual findings and should be addressed. Meta-analytic approaches are helpful to gauge overall effect sizes, and indeed, for some sub-domains of impulsivity, meta-analyses have been performed. Thus, Amlung et al. (2019) find enhanced temporal discounting in BED, although they focus on comparisons against normal weight controls, leaving aside possible confounds with BMI. Cury et al. (2020) report no significant differences between BED subjects and controls on the SSRT, Stroop task, and gambling tasks. However, importantly, neither are able to pin down the reason(s) for the divergent results across the original studies. In addition to confounding effects of comorbidity, treatment, sample type and possible p-hacking that Cury et al. (2020) suggest, we propose that this heterogeneity may be due to a disregard for a specific clinical feature of BED, methodological limitations or a combination of both (detailed below):

It is something of a truism that loss of control in BED is not constant but state-dependent, and this is taken into account in many studies. Yet it is often tacitly assumed that the loss of control experienced by BED patients is similar to the loss of control experienced by e.g. drug or alcohol users, i.e., often triggered by disorder relevant cues in the environment (see e.g. Berridge and Robinson, 2016; Cofresí et al., 2019 for reviews). Indeed, we do see enhanced food cue 
reactivity or attentional bias towards food cues in BED (Deluchi et al., 2017; Lyu et al., 2016; Popien et al., 2015; Schag et al., 2013; Schmidt et al., 2016; Schmitz et al., 2015, 2014; Sperling et al., 2017). Hence, food stimuli are often used in paradigms assessing impulsivity in BED. But there is little evidence of enhanced motor impulsivity in the face of or interference by food stimuli, suggesting that this bias does not straightforwardly translate into a control deficit, although explicit investigations of the influence of food stimuli on the other aspects of impulsivity are as yet missing. Instead, negative mood states may be more essential in BED. Mood disorders are common comorbidities in BED (Hudson et al., 2007). Likewise, a wellestablished finding from studies using self-report instruments is that patients have high "negative urgency", i.e. a tendency to act impulsively when distressed (Kelly et al., 2014; Kenny et al., 2019; Racine et al., 2015; Ralph-Nearman et al., 2020), which also correlates with symptom severity. This aspect is not usually captured by the paradigms used to measure impulsivity in task-based designs, which may have contributed to the heterogeneity within the impulsivity literature. To account for this, negative mood as a potential favorable condition or trigger for in-the-moment loss of control must be experimentally manipulated. For example, negative mood could be induced either within a task, e.g. through a large loss in a wheel of fortune draw (e.g. Eldar and Niv, 2015) or prior to it, e.g. by watching a film (Westermann et al., 1996). Notably, Danner et al. (2013) have done the latter and found an increase in impulsive behavior after punishments in BE participants after a negative mood induction. Other state factors may also play a role in triggering loss of behavioral control, such as physiological or hedonic hunger. Incorporating such factors may help improve consistency across studies in the future.

In addition, certain methodological issues may have played a part in producing heterogeneous results across studies. First, because BED frequently overlaps with obesity (Hudson et al., 2007; Kessler et al., 2013), there is a great risk of confounding effects of BMI and LOC eating. Thus, group differences might emerge in comparisons of BED participants against NW controls 
but vanish in comparisons against OW controls. Although many studies have compared all three groups (BED, and NW and OW controls), this practice is not yet pervasive and may have exacerbated the muddled picture we see. Second, in cross-sectional studies like those considered here, samples typically include individuals at varying stages of the illness. This means that changes in the cognitive profile that might parallel illness progression are disregarded. For example, a more compulsive profile in BED could develop from a more impulsive profile, not unlike what has been suggested in the addiction literature (Belin et al., 2008). Such an effect would be masked in cross-sectional studies and might result in inconsistent findings across samples. Third, the tasks employed might be unreliable. Low reliability dramatically reduces correlations between task readouts and individual differences such as symptom dimensions (Hedge et al., 2018). Indeed, many of the tasks that have been used to assess impulsivity in BED have poor retest reliability, e.g. the IGT (Buelow and Barnhart, 2017), Game of Dice (Buelow and Barnhart, 2017), and SSRT (Hedge et al., 2018) (for an overview, see Enkavi et al., 2019; Hedge et al., 2018). While such methodological issues do not apply exclusively to studies on impulsivity in BED, they may be of particular importance here.

Hence, although findings regarding impulsivity in LOC eating and BED are quite incongruous, the idea that it might contribute to loss of control over eating behavior cannot be dismissed yet. Future studies should attempt to distil its role using more careful designs. Negative mood as a potential catalyst for impulsive behavior in BED should be taken into account and explicitly manipulated experimentally. Additionally, great care should be taken to control for the differential effects of excess weight and LOC eating; to ascertain that the tasks employed are reliable; and to capture disease dynamics. The latter could be achieved by statistically modelling illness duration, by conducting longitudinal studies, or by studying adolescent/early adulthood samples, as this is the period when BED typically arises and effects of chronicity 
are unlikely to occur (Hudson et al., 2007; Kessler et al., 2013; Manwaring et al., 2006; Mustelin et al., 2015; Spurrell et al., 1997).

\subsection{Enhanced compulsivity in BED?}

The literature on compulsive behavior in BED is less ample than the impulsivity literature and many findings remain to be replicated. Nonetheless, in keeping with the notion of binge eating as a compulsive behavior (Gillan et al., 2016b; Kakoschke et al., 2019; Moore et al., 2017; Voon et al., 2015b), we found relatively consistent evidence of impaired goal-directed control and cognitive flexibility in BE. The latter is evident mainly in tasks where participants must adapt their behavior to changing rewards and punishments (reward-related cognitive flexibility), and less so in tasks where participants must merely shift attention or decisionmaking based on changing rules (set-shifting). Reinforcement learning is crucially implicated in both reward-related cognitive flexibility and goal-directed control tasks, where behaviors were explicitly rewarded or punished. The evidence thus lends itself to the speculation that reinforcement learning difficulties might play a role. That is, certain failures of behavioral control in BED may be linked to alterations of the way previous experiences of reward and punishment are integrated when making decisions in the present.

One way to investigate this is by drawing on biologically plausible computational reinforcement learning models (i.e., algorithms that imitate behavior) when analyzing task data(e.g. Morris et al., 2016; Reiter et al., 2017; Voon et al., 2015a). Fitted to the individual's data, the parameters of a model can yield insights as to the mechanistic differences that might underly divergences in behavior. Early results using this approach indicate a distortion of how punishments, in contrast to rewards, shape reinforcement learning in BE (Banca et al., 2016; Morris et al., 2016). Moreover, they suggest that BED patients have difficulty adaptively exploiting their knowledge of the rewarding or punishing consequences of actions when making decisions (Morris et al., 2016; Reiter et al., 2017), as well as their knowledge of the 
(task) environment when it comes to planning actions in a goal directed manner (Voon et al., 2015b).

Integrating these insights into the framework of impulsivity and compulsivity can be difficult. For example, they suggest that low performance on a reversal learning task in BE came about as a result of excessive switching between response options (Reiter et al., 2017) - an instable behavioral pattern reflective of maladaptive exploration. In contrast to perseveration, overexploration appears impulsive rather than compulsive, and has in fact been associated with impulsive disorders such as ADHD in the past (Hauser et al., 2014). This challenges any sharp divide between compulsivity and impulsivity. Indeed, a recent line of factor analytic work in large samples suggests that they overlap at least partially (Chamberlain et al., 2018; Gillan et al., 2016a; Tiego et al., 2019). One study indicates that three latent factors may be in play (Tiego et al., 2019). First, "impulsivity", characterized especially by risk and reward seeking as well as lack of forethought; second, "compulsivity", characterized by risk aversion and harm avoidance as well as increased need for premeditation; and third, "disinhibition", characterized by impulsivity (as per the UPPS), behavioral approach, intolerance of uncertainty and obsessive beliefs (Tiego et al., 2019). Partly because this work has not yet been extended to the realm of task-based impulsivity and compulsivity metrics, partly for the sake of readability, we have assigned tasks to one domain or the other in our review. However, future research may benefit from a focus on the neurobehavioral substrates that impulsivity and compulsivity share (e.g. reduced goal-directed control) and the processes that may uniquely dissociate them (e.g. choice switching versus perseveration) (Deserno and Hauser, 2020). To do this, it will be important to identify fine-grained metrics that reflect distinct components of task performance.

Going forward, alterations that have already been observed should be further investigated using a two-pronged strategy. One line of research should explore them in more detail, asking how they relate to neurochemical differences observed between patients and controls (Joutsa 
et al., 2018; Majuri et al., 2017, 2016). Likewise, it should be tested whether they might be more pronounced in punishment-avoidance contexts, consistent with reports of increased desire to (binge) eat in negative mood and stress states in BED (Rosenberg et al., 2013; Schulz and Laessle, 2012). This is possible thanks to newly developed tasks and models that can capture state-dependent mood as well as neurochemical effects (Eldar and Niv, 2015; Michely et al., 2020). The other line of research should examine their relationship with clinical outcomes, asking e.g. how they relate to its prominent clinical onset in adolescence, and whether they wax and wane with BED symptom severity, in keeping with a mechanistic role in the disorder.

\subsection{Translational Shortcomings.}

In addition to the specific remarks above, we note that there is little in the way of translational work (with a few notable exceptions). Thus, there are few animal studies overall, but particularly in the impulsivity domain, as well as a relative lack of studies attempting to directly replicate rodent findings in humans or vice versa. Likewise, there are few neurofunctional investigations, despite growing evidence of substantial neurostructural and neurochemical alterations in BED (Cambridge et al., 2013; Dodds et al., 2012; Filbey et al., 2012; Fleck et al., 2019; Joutsa et al., 2018; Majuri et al., 2017, 2016; Schäfer et al., 2010; Wang et al., 2011). This should be addressed in the future. Moreover, in the few studies that did report neuroimaging data in addition to behavioral data, the latter could often not be related to the former (Balodis et al., 2013; Lee et al., 2017; Oliva et al., 2019). This could once more reflect a problem with poor task reliability, which invariably reduces correlations with other measures, including neuroimaging measures (Elliott et al., 2020; Hedge et al., 2018). We can therefore not stress enough that it is essential that we use reliable tasks when investigating individual differences in behavior and their associated brain signatures. 


\subsection{Limitations}

In this review, we focused on case-control studies looking into differences between groups of individuals with binge eating symptoms (or more frequently binge eating disorder) and either normal- or overweight. This approach is limited on three accounts. First, limiting comparisons to one category of disorder with healthy individuals precludes the discovery of transdiagnostically similar alterations of behavioral impulsivity and compulsivity, e.g., across eating disorders or with substance misuse disorders, attention deficit hyperactivity disorder, or obsessive compulsive disorder. However, we have reason to believe from self-report based studies that the overlap is considerable (Tiego et al., 2019). This should be taken into account in the future. Second, binge eating occurs transdiagnostically across eating disorders. Although this is clinically relevant, our approach meant that we could not include studies on people with e.g., bulimia nervosa or anorexia. This is because loss of control eating cannot be differentiated from other symptoms (e.g., compensatory behaviors) in those populations. Similarly, we could not include direct comparisons between eating disorder phenotypes because they confer information mostly about the features that distinguish them rather than those that they share (e.g. binge eating). Third, and relatedly, disregarding correlations with symptom severity runs the risk of overlooking subtle associations as well as overinterpreting group differences that turn out not to be associated with symptom severity.

We have taken this approach in order to maintain focus. However, there are more and more well-powered, population-based studies that sample multiple metrics at once - such as different symptom scales and self-report but also task-based metrics of impulsivity and compulsivity (e.g. Gillan et al., 2016a). This allows for simultaneous comparison of the relationship of different types of psychiatric symptoms with these metrics. In addition, it allows for comparisons between the metrics themselves, yielding vital insights into their relationship with one another. Hook et al., (2021) recently stressed the importance of using transdiagnostically valid scales of compulsivity in such work, a suggestion that will hopefully 
be taken up. Future reviews will be able to take a more transdiagnostic and dimensional view, which promises to be fruitful.

In addition, we have chosen not to perform meta-analysis, precluding the quantification of effects across studies. We made this decision because a recent review and meta-analysis on executive function in BED covers many of the tasks relevant to impulsivity and compulsivity for which meta-analysis is possible, i.e., motor impulsivity, risky decision-making, interference control, and set shifting (Cury et al., 2020). Another covers delay discounting (Amlung et al., 2019). For the other domains, e.g., reflection impulsivity, reward-related cognitive flexibility, or goal-directed control, the number of studies was insufficient to perform meta-analysis. Notwithstanding, we feel that our more qualitative approach incorporating animal and psychophysiological work adds important perspectives that meta-analyses alone do not afford.

Finally, we have not included studies on neurostructural and neurochemical alterations in BED, nor have we considered treatment studies. Yet such alterations are likely relevant to impulsive and compulsive behavior. While this would have gone beyond the scope of the current review with its clear focus on behavioral data, it would be valuable to integrate these insights in the future.

\subsection{Conclusion and recommendations for future studies.}

Self-report measures point towards enhanced impulsivity and compulsivity in BED, but they are agnostic as to the mechanisms that might lead to impulsive and compulsive behavior in in the moment. Task-based research promises insight here, but our review shows that the literature on impulsive behavior in BED is extremely heterogeneous and does not yield unequivocal conclusions. The literature on compulsive behavior implicates a potential role of a reinforcement learning deficit. We propose that future research should focus on (1) taking into account momentary mood state as a possible catalyst of impulsive, and potentially also compulsive behavior; (2) more consistently controlling for confounding variables such as BMl; 
(3) capturing disease dynamics in longitudinal designs or by controlling for illness duration, ideally in developmental samples; (4) using reliable behavioral measures so as to be able to pick up correlations with individual differences and brain responses; (5) translating animal work to humans and back, and behavioral to neuroimaging studies; and (6) further interrogating the relatively consistent findings in the compulsivity domain, especially in view of a potential role of a reinforcement learning deficit. To do this, we suggest adopting computational approaches, which can yield clues as to process alterations that might lead to behavioral differences, and can be applied across measurement modalities in human and animal studies (Alsiö et al., 2019; Gläscher and O’Doherty, 2010; Groman et al., 2019; Hirokawa et al., 2019) . 


\section{Acknowledgements}

This work was supported by the IFB Adiposity Diseases, Federal Ministry of Education and Research (BMBF), Germany, GN: 01EO1501 (MW, NH, AH, LD). NH receives a scholarship from the FAZIT foundation. AH receives funding from the German Research Foundation (DFG), within the framework of the Collaborative Research Centre 1052 'Obesity Mechanisms', project number 209933838. LD receives funding from the German Research Foundation (DFG) as part of Collaborative Research Centre 265 "Losing and Regaining Control over drug intake" (Project A02). Finally, the Max Planck Society has kindly covered overheads for $\mathrm{MW}, \mathrm{NH}$, and $\mathrm{AH}$.

\section{Disclosures}

$\mathrm{MW}, \mathrm{LD}, \mathrm{NH}$, and $\mathrm{AH}$ report no biomedical financial interests or potential conflicts of interest. 


\section{References}

Aloi, M., Rania, M., Caroleo, M., Bruni, A., Palmieri, A., Cauteruccio, M.A., De Fazio, P., Segura-García, C., 2015. Decision making, central coherence and set-shifting: a comparison between Binge Eating Disorder, Anorexia Nervosa and Healthy Controls. BMC Psychiatry 15, 6. https://doi.org/10.1186/s12888-015-0395-z

Aloi, M., Rania, M., de Filippis, R., Segura-Garcia, C., 2020. Weight and age do not account for a worse executive functioning among BED-obese patients. Eat. Weight Disord. 25, 373-377. https://doi.org/10.1007/s40519-018-0608-9

Alsiö, J., Phillips, B.U., Sala-Bayo, J., Nilsson, S.R.O., Calafat-Pla, T.C., Rizwand, A., Plumbridge, J.M., López-Cruz, L., Dalley, J.W., Cardinal, R.N., Mar, A.C., Robbins, T.W., 2019. Dopamine D2-like receptor stimulation blocks negative feedback in visual and spatial reversal learning in the rat: behavioral and computational evidence. Psychopharmacology (Berl). 236, 2307-2323. https://doi.org/10.1007/s00213-01905296-y

American Psychiatric Association, Association, A.P., 2013. Diagnostic and statistical manual of mental disorders (DSM-5®). American Psychiatric Pub.

Amlung, M., Marsden, E., Holshausen, K., Morris, V., Patel, H., Vedelago, L., Naish, K.R., Reed, D.D., McCabe, R.E., 2019. Delay Discounting as a Transdiagnostic Process in Psychiatric Disorders: A Meta-analysis. JAMA psychiatry 76, 1176-1186. https://doi.org/10.1001/jamapsychiatry.2019.2102

Anastasio, N.C., Stutz, S.J., Price, A.E., Davis-Reyes, B.D., Sholler, D.J., Ferguson, S.M., Neumaier, J.F., Moeller, F.G., Hommel, J.D., Cunningham, K.A., 2019. Convergent neural connectivity in motor impulsivity and high-fat food binge-like eating in male 
Sprague-Dawley rats. Neuropsychopharmacology 44, 1752-1761. https://doi.org/10.1038/s41386-019-0394-8

Antunes, L.C., Elkfury, J.L., Parizotti, C.S., Brietzke, A.P., Bandeira, J.S., Torres, I.L. da S., Fregni, F., Caumo, W., 2020. Longer Cortical Silent Period Length Is Associated to Binge Eating Disorder: An Exploratory Study. Front. psychiatry 11, 559966. https://doi.org/10.3389/fpsyt.2020.559966

Badrasawi, M.M., Zidan, S.J., 2019. Binge eating symptoms prevalence and relationship with psychosocial factors among female undergraduate students at Palestine Polytechnic University: a cross-sectional study. J. Eat. Disord. 7, 33. https://doi.org/10.1186/s40337019-0263-1

Balodis, I.M., Molina, N.D., Kober, H., Worhunsky, P.D., White, M.A., Sinha, R., Grilo, C.M., Potenza, M.N., 2013. Divergent neural substrates of inhibitory control in binge eating disorder relative to other manifestations of obesity. Obesity (Silver Spring). 21, 367-377. https://doi.org/10.1002/oby.20068

Banca, P., Harrison, N.A., Voon, V., 2016. Compulsivity Across the Pathological Misuse of Drug and Non-Drug Rewards. Front. Behav. Neurosci. 10, 154. https://doi.org/10.3389/fnbeh.2016.00154

Bartholdy, S., O’Daly, O.G., Campbell, I.C., Banaschewski, T., Barker, G., Bokde, A.L.W., Bromberg, U., Büchel, C., Quinlan, E.B., Desrivières, S., Flor, H., Frouin, V., Garavan, H., Gowland, P., Heinz, A., Ittermann, B., Martinot, J.-L., Paillère Martinot, M.-L., Nees, F., Orfanos, D.P., Poustka, L., Hohmann, S., Fröhner, J.H., Smolka, M.N., Walter, H., Whelan, R., Schumann, G., Schmidt, U., 2019. Neural Correlates of Failed Inhibitory Control as an Early Marker of Disordered Eating in Adolescents. Biol. Psychiatry 85, 956-965. https://doi.org/10.1016/j.biopsych.2019.01.027 
Bartholdy, S., Rennalls, S., Danby, H., Jacques, C., Campbell, I.C., Schmidt, U., O’Daly, O.G., 2017a. Temporal Discounting and the Tendency to Delay Gratification across the Eating Disorder Spectrum. Eur. Eat. Disord. Rev. 25, 344-350. https://doi.org/10.1002/erv.2513

Bartholdy, S., Rennalls, S.J., Jacques, C., Danby, H., Campbell, I.C., Schmidt, U., O’Daly, O.G., 2017b. Proactive and reactive inhibitory control in eating disorders. Psychiatry Res. 255, 432-440. https://doi.org/10.1016/j.psychres.2017.06.073

Bechara, A., Damasio, A.R., Damasio, H., Anderson, S.W., 1994. Insensitivity to future consequences following damage to human prefrontal cortex. Cognition 50, 7-15. https://doi.org/https://doi.org/10.1016/0010-0277(94)90018-3

Belin, D., Mar, A.C., Dalley, J.W., Robbins, T.W., Everitt, B.J., 2008. High Impulsivity Predicts the Switch to Compulsive Cocaine-Taking. Science (80-. ). 320, 1352 LP - 1355. https://doi.org/10.1126/science.1158136

Berg, E.A., 1948. A Simple Objective Technique for Measuring Flexibility in Thinking. J. Gen. Psychol. 39, 15-22. https://doi.org/10.1080/00221309.1948.9918159

Berridge, K.C., Robinson, T.E., 2016. Liking, wanting, and the incentive-sensitization theory of addiction. Am. Psychol. 71, 670-679. https://doi.org/10.1037/amp0000059

Blume, M., Schmidt, R., Hilbert, A., 2018. Executive Functioning in Obesity, Food Addiction, and Binge-Eating Disorder. Nutrients 11. https://doi.org/10.3390/nu11010054

Boulanger, H., Tebeka, S., Girod, C., Lloret-Linares, C., Meheust, J., Scott, J., Guillaume, S., Courtet, P., Bellivier, F., Delavest, M., 2018. Binge eating behaviors in bipolar disorders. J. Affect. Disord. 225, 482-488. https://doi.org/10.1016/j.jad.2017.08.068

Brand, M., Fujiwara, E., Borsutzky, S., Kalbe, E., Kessler, J., Markowitsch, H.J., 2005. Decision-making deficits of korsakoff patients in a new gambling task with explicit rules: 
associations with executive functions. Neuropsychology 19, 267-277. https://doi.org/10.1037/0894-4105.19.3.267

Braun, J., El-Gabalawy, R., Sommer, J.L., Pietrzak, R.H., Mitchell, K., Mota, N., 2019. Trauma Exposure, DSM-5 Posttraumatic Stress, and Binge Eating Symptoms: Results From a Nationally Representative Sample. J. Clin. Psychiatry 80. https://doi.org/10.4088/JCP.19m12813

Buelow, M.T., Barnhart, W.R., 2017. Test-Retest Reliability of Common Behavioral Decision Making Tasks. Arch. Clin. Neuropsychol. 33, 125-129. https://doi.org/10.1093/arclin/acx038

Burrows, T., Skinner, J., McKenna, R., Rollo, M., 2017. Food Addiction, Binge Eating Disorder, and Obesity: Is There a Relationship? Behav. Sci. . https://doi.org/10.3390/bs7030054

Cambridge, V.C., Ziauddeen, H., Nathan, P.J., Subramaniam, N., Dodds, C., Chamberlain, S.R., Koch, A., Maltby, K., Skeggs, A.L., Napolitano, A., Farooqi, I.S., Bullmore, E.T., Fletcher, P.C., 2013. Neural and behavioral effects of a novel mu opioid receptor antagonist in binge-eating obese people. Biol. Psychiatry 73, 887-894. https://doi.org/10.1016/j.biopsych.2012.10.022

Cano, A.M., Murphy, E.S., Lupfer, G., 2016. Delay discounting predicts binge-eating in Wistar rats. Behav. $\quad$ Processes 132, 1-4. https://doi.org/https://doi.org/10.1016/j.beproc.2016.08.011

Carriere, C., Michel, G., Féart, C., Pellay, H., Onorato, O., Barat, P., Thibault, H., 2019. Relationships between emotional disorders, personality dimensions, and binge eating disorder in French obese adolescents. Arch. Pédiatrie 26, 138-144. https://doi.org/https://doi.org/10.1016/j.arcped.2019.02.008 
Carter, J.C., Van Wijk, M., Rowsell, M., 2019. Symptoms of 'food addiction' in binge eating disorder using the Yale Food Addiction Scale version 2.0. Appetite 133, 362-369. https://doi.org/10.1016/J.APPET.2018.11.032

Chamberlain, S.R., Stochl, J., Redden, S.A., Grant, J.E., 2018. Latent traits of impulsivity and compulsivity: toward dimensional psychiatry. Psychol. Med. 48, 810-821. https://doi.org/10.1017/S0033291717002185

Chawla, A., Cordner, Z.A., Boersma, G., Moran, T.H., 2017. Cognitive impairment and gene expression alterations in a rodent model of binge eating disorder. Physiol. Behav. 180, 78-90. https://doi.org/10.1016/j.physbeh.2017.08.004

Clark, L., Robbins, T.W., Ersche, K.D., Sahakian, B.J., 2006. Reflection Impulsivity in Current and Former Substance Users. Biol. Psychiatry 60, 515-522. https://doi.org/https://doi.org/10.1016/j.biopsych.2005.11.007

Cofresí, R.U., Bartholow, B.D., Piasecki, T.M., 2019. Evidence for incentive salience sensitization as a pathway to alcohol use disorder. Neurosci. Biobehav. Rev. 107, 897926. https://doi.org/https://doi.org/10.1016/j.neubiorev.2019.10.009

Cools, R., Clark, L., Owen, A.M., Robbins, T.W., 2002. Defining the Neural Mechanisms of Probabilistic Reversal Learning Using Event-Related Functional Magnetic Resonance Imaging. J. Neurosci. 22, 4563 LP - 4567. https://doi.org/10.1523/JNEUROSCI.22-1104563.2002

Córdova, M.E., Schiavon, C.C., Busnello, F.M., Reppold, C.T., 2017. Nutritional and Neuropsychological Profile of the Executive Functions on Binge Eating Disorder in Obese Adults. Nutr. Hosp. https://doi.org/10.20960/nh.1151

Cury, M.E.G., Berberian, A., Scarpato, B.S., Kerr-Gaffney, J., Santos, F.H., Claudino, A.M., 
2020. Scrutinizing Domains of Executive Function in Binge Eating Disorder: A Systematic Review and Meta-Analysis. Front. Psychiatry 11, 288. https://doi.org/10.3389/fpsyt.2020.00288

Cyders, M.A., Coskunpinar, A., 2011. Measurement of constructs using self-report and behavioral lab tasks: Is there overlap in nomothetic span and construct representation for $\begin{array}{lllll}\text { impulsivity? } & \text { Clin. } & \text { Psychol. } & \text { Rev. }\end{array}$ https://doi.org/https://doi.org/10.1016/j.cpr.2011.06.001

Danner, U.N., Evers, C., Sternheim, L., van Meer, F., van Elburg, A.A., Geerets, T.A.M., Breteler, L.M.T., de Ridder, D.T.D., 2013. Influence of negative affect on choice behavior in individuals with binge eating pathology. Psychiatry Res. 207, 100-106. https://doi.org/10.1016/j.psychres.2012.10.016

Danner, U.N., Ouwehand, C., van Haastert, N.L., Hornsveld, H., de Ridder, D.T.D., 2012. Decision-making impairments in women with binge eating disorder in comparison with obese and normal weight women. Eur. Eat. Disord. Rev. 20, e56-62. https://doi.org/10.1002/erv.1098

Daugherty, T.K., Quay, H.C., 1991. Response Perseveration and Delayed Responding in Childhood Behavior Disorders. J. Child Psychol. Psychiatry 32, 453-461. https://doi.org/10.1111/j.1469-7610.1991.tb00323.x

Davis, C., Patte, K., Curtis, C., Reid, C., 2010. Immediate pleasures and future consequences. A neuropsychological study of binge eating and obesity. Appetite 54, 208-213. https://doi.org/10.1016/j.appet.2009.11.002

Daw, N.D., Gershman, S.J., Seymour, B., Dayan, P., Dolan, R.J., 2011. Model-based influences on humans' choices and striatal prediction errors. Neuron 69, 1204-1215. https://doi.org/10.1016/j.neuron.2011.02.027 
de França, G.V.A., Gigante, D.P., Olinto, M.T.A., 2014. Binge eating in adults: prevalence and association with obesity, poor self-rated health status and body dissatisfaction. Public Health Nutr. 17, 932-938. https://doi.org/DOI: 10.1017/S1368980013000591

de Wit, S., Kindt, M., Knot, S.L., Verhoeven, A.A.C., Robbins, T.W., Gasull-Camos, J., Evans, M., Mirza, H., Gillan, C.M., 2018. Shifting the balance between goals and habits: Five failures in experimental habit induction. J. Exp. Psychol. Gen. 147, 1043-1065. https://doi.org/10.1037/xge0000402

Deal, L.S., Wirth, R.J., Gasior, M., Herman, B.K., McElroy, S.L., 2015. Validation of the yalebrown obsessive compulsive scale modified for binge eating. Int. J. Eat. Disord. 48, 9941004. https://doi.org/10.1002/eat.22407

Deluchi, M., Costa, F.S., Friedman, R., Gonçalves, R., Bizarro, L., 2017. Attentional bias to unhealthy food in individuals with severe obesity and binge eating. Appetite 108, 471476. https://doi.org/https://doi.org/10.1016/j.appet.2016.11.012

Deserno, L., Hauser, T.U., 2020. Beyond a Cognitive Dichotomy: Can Multiple Decision Systems Prove Useful to Distinguish Compulsive and Impulsive Symptom Dimensions? Biol. Psychiatry. https://doi.org/10.1016/j.biopsych.2020.03.004

Dingemans, A.E., Vanhaelen, C.B., Aardoom, J.J., van Furth, E.F., 2019. The influence of depressive symptoms on executive functioning in binge eating disorder: A comparison of patients and non-obese healthy controls. Psychiatry Res. 274, 138-145. https://doi.org/https://doi.org/10.1016/j.psychres.2019.02.033

Dodds, C.M., O’Neill, B., Beaver, J., Makwana, A., Bani, M., Merlo-Pich, E., Fletcher, P.C., Koch, A., Bullmore, E.T., Nathan, P.J., 2012. Effect of the dopamine D3 receptor antagonist GSK598809 on brain responses to rewarding food images in overweight and obese binge eaters. Appetite 59, 27-33. https://doi.org/10.1016/j.appet.2012.03.007 
Downes, J.J., Roberts, A.C., Sahakian, B.J., Evenden, J.L., Morris, R.G., Robbins, T.W., 1989. Impaired extra-dimensional shift performance in medicated and unmedicated Parkinson's disease: Evidence for a specific attentional dysfunction. Neuropsychologia 27, 1329_ 1343. https://doi.org/https://doi.org/10.1016/0028-3932(89)90128-0

Duchesne, M., Paulo, M., Appolinário, J.C., Freitas, S.R. de, Coutinho, G., Santos, C., Coutinho, W., 2010. Assessment of executive functions in obese individuals with binge eating disorder. Rev. Bras. Psiquiatr. 32, 381-388. https://doi.org/10.1590/S151644462010000400011

Eldar, E., Niv, Y., 2015. Interaction between emotional state and learning underlies mood instability. Nat. Commun. 6, 6149. https://doi.org/10.1038/ncomms7149

Elliott, M.L., Knodt, A.R., Ireland, D., Morris, M.L., Poulton, R., Ramrakha, S., Sison, M.L., Moffitt, T.E., Caspi, A., Hariri, A.R., 2020. What is the test-retest reliability of common task-fMRI measures? New empirical evidence and a meta-analysis. Psychol. Sci. 681700. https://doi.org/10.1101/681700

Eneva, K.T., Arlt, J.M., Yiu, A., Murray, S.M., Chen, E.Y., 2017. Assessment of executive functioning in binge-eating disorder independent of weight status. Int. J. Eat. Disord. 50, 942-951. https://doi.org/10.1002/eat.22738

Enkavi, A.Z., Eisenberg, I.W., Bissett, P.G., Mazza, G.L., MacKinnon, D.P., Marsch, L.A., Poldrack, R.A., 2019. Large-scale analysis of test-retest reliabilities of self-regulation measures. Proc. Natl. Acad. Sci. 116, 5472 LP - 5477. https://doi.org/10.1073/pnas.1818430116

Eriksen, B.A., Eriksen, C.W., 1974. Effects of noise letters upon the identification of a target letter in a nonsearch task. Percept. Psychophys. 16, 143-149. https://doi.org/10.3758/BF03203267 
Everitt, B.J., Robbins, T.W., 2005. Neural systems of reinforcement for drug addiction: from actions to habits to compulsion. Nat. Neurosci. 8, 1481-1489. https://doi.org/10.1038/nn1579

Fabricatore, A.N., Wadden, T.A., 2006. Obesity. Annu. Rev. Clin. Psychol. 2, 357-377. https://doi.org/10.1146/annurev.clinpsy.2.022305.095249

Fairburn, C.G., Cooper, Z., Doll, H.A., Norman, P., O'Connor, M., 2000. The natural course of bulimia nervosa and binge eating disorder in young women. Arch. Gen. Psychiatry 57, $659-665$.

Farstad, S.M., von Ranson, K.M., Hodgins, D.C., El-Guebaly, N., Casey, D.M., Schopflocher, D.P., 2015. The influence of impulsiveness on binge eating and problem gambling: $A$ prospective study of gender differences in Canadian adults. Psychol. Addict. Behav. J. Soc. Psychol. Addict. Behav. 29, 805-812. https://doi.org/10.1037/adb0000069

Filbey, F.M., Myers, U.S., Dewitt, S., 2012. Reward circuit function in high BMI individuals with compulsive overeating: similarities with addiction. Neuroimage 63, 1800-1806. https://doi.org/10.1016/j.neuroimage.2012.08.073

Fineberg, N.A., Chamberlain, S.R., Goudriaan, A.E., Stein, D.J., Vanderschuren, L.J.M.J., Gillan, C.M., Shekar, S., Gorwood, P.A.P.M., Voon, V., Morein-Zamir, S., Denys, D., Sahakian, B.J., Moeller, F.G., Robbins, T.W., Potenza, M.N., 2014. New developments in human neurocognition: clinical, genetic, and brain imaging correlates of impulsivity and compulsivity. CNS Spectr. 19, 69-89. https://doi.org/10.1017/S1092852913000801

Fleck, D.E., Eliassen, J.C., Guerdjikova, A.I., Mori, N., Williams, S., Blom, T.J., Beckwith, T., Tallman, M.J., Adler, C.M., DelBello, M.P., Strakowski, S.M., McElroy, S.L., 2019. Effect of lisdexamfetamine on emotional network brain dysfunction in binge eating disorder. Psychiatry Res. Neuroimaging 286, $53-59$. 
https://doi.org/10.1016/j.pscychresns.2019.03.003

Fletcher, P.C., Kenny, P.J., 2018. Food addiction: a valid concept? Neuropsychopharmacol. Off. Publ. Am. Coll. Neuropsychopharmacol. 43, 2506-2513. https://doi.org/10.1038/s41386-018-0203-9

Furlong, T.M., Jayaweera, H.K., Balleine, B.W., Corbit, L.H., 2014. Binge-like consumption of a palatable food accelerates habitual control of behavior and is dependent on activation of the dorsolateral striatum. J. Neurosci. 34, 5012-5022. https://doi.org/10.1523/JNEUROSCI.3707-13.2014

Galioto, R., Spitznagel, M.B., Strain, G., Devlin, M., Cohen, R., Paul, R., Crosby, R.D., Mitchell, J.E., Gunstad, J., 2012. Cognitive function in morbidly obese individuals with and without binge eating disorder. Compr. Psychiatry 53, 490-495. https://doi.org/10.1016/J.COMPPSYCH.2011.09.002

Gearhardt, A.N., Corbin, W.R., Brownell, K.D., 2016. Development of the Yale Food Addiction Scale Version 2.0. Psychol. Addict. Behav. 30, 113-121. https://doi.org/10.1037/adb0000136

Gearhardt, A.N., Corbin, W.R., Brownell, K.D., 2009. Preliminary validation of the Yale Food Addiction Scale. Appetite 52, 430-436. https://doi.org/10.1016/j.appet.2008.12.003

Gillan, C.M., Kosinski, M., Whelan, R., Phelps, E.A., Daw, N.D., 2016a. Characterizing a psychiatric symptom dimension related to deficits in goal-directed control. Elife 5 . https://doi.org/10.7554/eLife.11305

Gillan, C.M., Robbins, T.W., Sahakian, B.J., van den Heuvel, O.A., van Wingen, G., 2016b. The role of habit in compulsivity. Eur. Neuropsychopharmacol. J. Eur. Coll. Neuropsychopharmacol. 26, 828-840. https://doi.org/10.1016/j.euroneuro.2015.12.033 
Gläscher, J.P., O'Doherty, J.P., 2010. Model-based approaches to neuroimaging: combining reinforcement learning theory with fMRI data. WIREs Cogn. Sci. 1, 501-510. https://doi.org/10.1002/wcs.57

Grant, J.E., Chamberlain, S.R., 2019. Neurocognitive findings in young adults with binge eating disorder. Int. J. Psychiatry Clin. Pract. https://doi.org/10.1080/13651501.2019.1687724

Groman, S.M., Massi, B., Mathias, S.R., Lee, D., Taylor, J.R., 2019. Model-Free and ModelBased Influences in Addiction-Related Behaviors. Biol. Psychiatry 85, 936-945. https://doi.org/10.1016/j.biopsych.2018.12.017

Hauser, T.U., Iannaccone, R., Ball, J., Mathys, C., Brandeis, D., Walitza, S., Brem, S., 2014. Role of the Medial Prefrontal Cortex in Impaired Decision Making in Juvenile AttentionDeficit/Hyperactivity Disorder. JAMA Psychiatry 71, 1165-1173. https://doi.org/10.1001/jamapsychiatry.2014.1093

Heal, D.J., Goddard, S., Brammer, R.J., Hutson, P.H., Vickers, S.P., 2016. Lisdexamfetamine reduces the compulsive and perseverative behavior of binge-eating rats in a novel food reward/punished responding conflict model. J. Psychopharmacol. 30, 662-675. https://doi.org/10.1177/0269881116647506

Hedge, C., Powell, G., Sumner, P., 2018. The reliability paradox: Why robust cognitive tasks do not produce reliable individual differences. Behav. Res. Methods 50, 1166-1186. https://doi.org/10.3758/s13428-017-0935-1

Hege, M.A., Stingl, K.T., Kullmann, S., Schag, K., Giel, K.E., Zipfel, S., Preissl, H., 2015. Attentional impulsivity in binge eating disorder modulates response inhibition performance and frontal brain networks. Int. J. Obes. 39, 353-360. https://doi.org/10.1038/ijo.2014.99 
Heo, Y.-A., Duggan, S.T., 2017. Lisdexamfetamine: A Review in Binge Eating Disorder. CNS Drugs 31, 1015-1022. https://doi.org/10.1007/s40263-017-0477-1

Hirokawa, J., Vaughan, A., Masset, P., Ott, T., Kepecs, A., 2019. Frontal cortex neuron types categorically encode single decision variables. Nature 576, 446-451. https://doi.org/10.1038/s41586-019-1816-9

Hook, R.W., Grant, J.E., loannidis, K., Tiego, J., Yücel, M., Wilkinson, P., Chamberlain, S.R., 2021. Transdiagnostic measurement of impulsivity and compulsivity: A review of selfreport tools. Neurosci. Biobehav. Rev. 120, 455-469. https://doi.org/https://doi.org/10.1016/j.neubiorev.2020.10.007

Howard, M., Gregertsen, E.C., Hindocha, C., Serpell, L., 2020. Impulsivity and compulsivity in anorexia and bulimia nervosa: A systematic review. Psychiatry Res. 293, 113354. https://doi.org/10.1016/j.psychres.2020.113354

Hudson, J.I., Hiripi, E., Pope, H.G.J., Kessler, R.C., Pope Jr., H.G., Kessler, R.C., 2007. The prevalence and correlates of eating disorders in the National Comorbidity Survey Replication. Biol. Psychiatry 61, 348-358. https://doi.org/10.1016/j.biopsych.2006.03.040

Joutsa, J., Karlsson, H.K., Majuri, J., Nuutila, P., Helin, S., Kaasinen, V., Nummenmaa, L., 2018. Binge eating disorder and morbid obesity are associated with lowered mu-opioid receptor availability in the brain. Psychiatry Res. Neuroimaging 276, 41-45. https://doi.org/10.1016/J.PSCYCHRESNS.2018.03.006

Kakoschke, N., Aarts, E., Verdejo-García, A., 2019. The Cognitive Drivers of Compulsive Eating Behavior . Front. Behav. Neurosci.

Kelly, N.R., Bulik, C.M., Mazzeo, S.E., 2013. Executive functioning and behavioral impulsivity of young women who binge eat. Int. J. Eat. Disord. 46, 127-139. 
https://doi.org/10.1002/eat.22096

Kelly, N.R., Cotter, E.W., Mazzeo, S.E., 2014. Examining the role of distress tolerance and negative urgency in binge eating behavior among women. Eat. Behav. 15, 483-489. https://doi.org/https://doi.org/10.1016/j.eatbeh.2014.06.012

Kenny, T.E., Singleton, C., Carter, J.C., 2019. An examination of emotion-related facets of impulsivity in binge eating disorder. Eat. Behav. 32, 74-77. https://doi.org/10.1016/j.eatbeh.2018.12.006

Kessler, R.C., Berglund, P.A., Chiu, W.T., Deitz, A.C., Hudson, J.I., Shahly, V., AguilarGaxiola, S., Alonso, J., Angermeyer, M.C., Benjet, C., Bruffaerts, R., de Girolamo, G., de Graaf, R., Maria Haro, J., Kovess-Masfety, V., O’Neill, S., Posada-Villa, J., Sasu, C., Scott, K., Viana, M.C., Xavier, M., 2013. The Prevalence and Correlates of Binge Eating Disorder in the World Health Organization World Mental Health Surveys. Biol. Psychiatry 73, 904-914. https://doi.org/10.1016/j.biopsych.2012.11.020

Kirby, K.N., Petry, N.M., Bickel, W.K., 1999. Heroin addicts have higher discount rates for delayed rewards than non-drug-using controls. J. Exp. Psychol. Gen. https://doi.org/10.1037/0096-3445.128.1.78

Kittel, R., Schmidt, R., Hilbert, A., 2017. Executive functions in adolescents with binge-eating disorder and obesity. Int. J. Eat. Disord. 50, 933-941. https://doi.org/10.1002/eat.22714

Kollei, I., Rustemeier, M., Schroeder, S., Jongen, S., Herpertz, S., Loeber, S., 2018. Cognitive control functions in individuals with obesity with and without binge-eating disorder. Int. J. Eat. Disord. 51, 233-240. https://doi.org/10.1002/eat.22824

Kurtz, M.M., Ragland, J.D., Moberg, P.J., Gur, R.C., 2004. The Penn Conditional Exclusion Test: a new measure of executive-function with alternate forms of repeat administration. 
Arch. Clin. Neuropsychol. Off. J. Natl. Acad. Neuropsychol. 19, 191-201. https://doi.org/10.1016/S0887-6177(03)00003-9

Lee, J.E., Namkoong, K., Jung, Y.-C.C., 2017. Impaired prefrontal cognitive control over interference by food images in binge-eating disorder and bulimia nervosa. Neurosci. Lett. 651, 95-101. https://doi.org/10.1016/j.neulet.2017.04.054

Lejuez, C.W., Read, J.P., Kahler, C.W., Richards, J.B., Ramsey, S.E., Stuart, G.L., Strong, D.R., Brown, R.A., 2002. Evaluation of a behavioral measure of risk taking: the Balloon Analogue Risk Task (BART). J. Exp. Psychol. Appl. 8, 75.

LeMon, J. V., Sisk, C.L., Klump, K.L., Johnson, A.W., 2019. Reduced sensitivity to devaluation for instrumental but not consummatory behaviors in binge eating prone rats. Physiol. Behav. 206, 13-21. https://doi.org/10.1016/j.physbeh.2019.03.005

Liberati, A., Altman, D.G., Tetzlaff, J., Mulrow, C., Gøtzsche, P.C., loannidis, J.P.A., Clarke, M., Devereaux, P.J., Kleijnen, J., Moher, D., 2009. The PRISMA Statement for Reporting Systematic Reviews and Meta-Analyses of Studies That Evaluate Health Care Interventions: Explanation and Elaboration. PLOS Med. 6, e1000100.

Lipson, S.K., Sonneville, K.R., 2017. Eating disorder symptoms among undergraduate and graduate students at 12 U.S. colleges and universities. Eat. Behav. 24, 81-88. https://doi.org/10.1016/j.eatbeh.2016.12.003

Loeber, S., Rustemeier, M., Paslakis, G., Pietrowsky, R., Müller, A., Herpertz, S., 2018. Mood and restrained eating moderate food-associated response inhibition in obese individuals with binge eating disorder. Psychiatry Res. 264, 346-353. https://doi.org/10.1016/j.psychres.2018.03.081

Logan, G.D., Cowan, W.B., Davis, K.A., 1984. On the ability to inhibit simple and choice 
reaction time responses: a model and a method. J. Exp. Psychol. Hum. Percept. Perform. 10, 276-291. https://doi.org/10.1037//0096-1523.10.2.276

Lynam, D.R., Smith, G.T., Whiteside, S.P., Cyders, M.A., 2006. The UPPS-P: Assessing five personality pathways to impulsive behavior. West Lafayette, Purdue Univ.

Lyu, Z., Zheng, P., Chen, H., Jackson, T., 2017. Approach and inhibition responses to external food cues among average-weight women who binge eat and weight-matched controls. Appetite 108, 367-374. https://doi.org/10.1016/j.appet.2016.10.025

Lyu, Z., Zheng, P., Jackson, T., 2016. Attention Disengagement Difficulties among Average Weight Women Who Binge Eat. Eur. Eat. Disord. Rev. 24, 286-293. https://doi.org/10.1002/erv.2438

Lyu, Z., Zheng, P., Lu, S., Qin, M., 2018. Impaired Conflict Monitoring to Food Cues in Women Who Binge Eat. Front. Psychol. 9, 2585. https://doi.org/10.3389/fpsyg.2018.02585

MacLeod, C.M., 1991. Half a century of research on the Stroop effect: an integrative review. Psychol. Bull. 109, 163.

Majuri, J., Joutsa, J., Johansson, J., Voon, V., Alakurtti, K., Parkkola, R., Lahti, T., Alho, H., Hirvonen, J., Arponen, E., Forsback, S., Kaasinen, V., 2016. Dopamine and Opioid Neurotransmission in Behavioral Addictions : A Comparative PET Study in Pathological Gambling and Binge Eating 42, 1169-1177. https://doi.org/10.1038/npp.2016.265

Majuri, J., Joutsa, J., Johansson, J., Voon, V., Parkkola, R., Alho, H., Arponen, E., Kaasinen, V., 2017. Serotonin transporter density in binge eating disorder and pathological gambling: A PET study with [11C]MADAM. Eur. Neuropsychopharmacol. 27, 1281-1288. https://doi.org/https://doi.org/10.1016/j.euroneuro.2017.09.007

Manasse, S.M., Espel, H.M., Forman, E.M., Ruocco, A.C., Juarascio, A.S., Butryn, M.L., 
Zhang, F., Lowe, M.R., 2015a. The independent and interacting effects of hedonic hunger and executive function on binge eating. Appetite 89, 16-21. https://doi.org/http://dx.doi.org/10.1016/j.appet.2015.01.013

Manasse, S.M., Forman, E.M., Ruocco, A.C., Butryn, M.L., Juarascio, A.S., Fitzpatrick, K.K., 2015b. Do executive functioning deficits underpin binge eating disorder? A comparison of overweight women with and without binge eating pathology. Int. J. Eat. Disord. 48, 677-683. https://doi.org/10.1002/eat.22383

Manasse, S.M., Goldstein, S.P., Wyckoff, E., Forman, E.M., Juarascio, A.S., Butryn, M.L., Ruocco, A.C., Nederkoorn, C., 2016. Slowing down and taking a second look: Inhibitory deficits associated with binge eating are not food-specific. Appetite 96, 555-559. https://doi.org/10.1016/j.appet.2015.10.025

Manwaring, J.L., Green, L., Myerson, J., Strube, M.J., Wilfley, D.E., 2011. Discounting of various types of rewards by women with and without binge eating disorder: evidence for general rather than specific differences. Psychol. Rec. 61, 561.

Manwaring, J.L., Hilbert, A., Wilfley, D.E., Pike, K.M., Fairburn, C.G., Dohm, F.-A., StriegelMoore, R.H., 2006. Risk factors and patterns of onset in binge eating disorder. Int. J. Eat. Disord. 39, 101-107. https://doi.org/10.1002/eat.20208

McElroy, S.L., Guerdjikova, A.I., Mori, N., Munoz, M.R., Keck, P.E., 2015. Overview of the treatment of binge eating disorder. CNS Spectr. 20, 546-556. https://doi.org/DOI: $10.1017 / \mathrm{S} 1092852915000759$

Meule, A., Platte, P., 2015. Facets of impulsivity interactively predict body fat and binge eating in young $\quad$ women. $\quad$ Appetite $\quad$ 87, https://doi.org/https://doi.org/10.1016/j.appet.2015.01.003 
Michely, J., Eldar, E., Martin, I.M., Dolan, R.J., 2020. A mechanistic account of serotonin's impact on mood. Nat. Commun. 11, 2335. https://doi.org/10.1038/s41467-020-16090-2

Mobbs, O., Iglesias, K., Golay, A., Van der Linden, M., 2011. Cognitive deficits in obese persons with and without binge eating disorder. Investigation using a mental flexibility task. Appetite 57, 263-271. https://doi.org/10.1016/J.APPET.2011.04.023

Mole, T.B., Irvine, M.A., Worbe, Y., Collins, P., Mitchell, S.P., Bolton, S., Harrison, N.A., Robbins, T.W., Voon, V., 2015. Impulsivity in disorders of food and drug misuse. Psychol. Med. 45, 771-782. https://doi.org/10.1017/S0033291714001834

Moore, C.F., Blasio, A., Sabino, V., Cottone, P., 2018. Impulsive choice does not predict bingelike eating in rats. Behav. Pharmacol. 29.

Moore, C.F., Sabino, V., Koob, G.F., Cottone, P., 2017. Pathological Overeating: Emerging Evidence for a Compulsivity Construct. Neuropsychopharmacology. https://doi.org/10.1038/npp.2016.269

Morris, L.S., Baek, K., Kundu, P., Harrison, N.A., Frank, M.J., Voon, V., 2016. Biases in the Explore-Exploit Tradeoff in Addictions: The Role of Avoidance of Uncertainty. Neuropsychopharmacology 41, 940-948. https://doi.org/10.1038/npp.2015.208

Moshe, L., Bekker, L., Weller, A., 2017. A Potential Animal Model of Maladaptive Palatable Food Consumption Followed by Delayed Discomfort. Front. Neurosci. 11, 377. https://doi.org/10.3389/fnins.2017.00377

Muller, A., Brandl, C., Kiunke, W., Georgiadou, E., Horbach, T., Kohler, H., de Zwaan, M., Müller, A., Brandl, C., Kiunke, W., Georgiadou, E., Horbach, T., Köhler, H., de Zwaan, M., 2014. Food-independent tendency to disadvantageous decisions in obese individuals with regular binge eating. Compr. Psychiatry 55, 64-70. 
https://doi.org/10.1016/j.comppsych.2013.08.010

Mustelin, L., Raevuori, A., Hoek, H.W., Kaprio, J., Keski-Rahkonen, A., 2015. Incidence and weight trajectories of binge eating disorder among young women in the community. Int. J. Eat. Disord. 48, 1106-1112. https://doi.org/10.1002/eat.22409

Nasser, J.A., Gluck, M.E., Geliebter, A., 2004. Impulsivity and test meal intake in obese binge eating women. Appetite 43, 303-307. https://doi.org/10.1016/j.appet.2004.04.006

Oliva, R., Morys, F., Horstmann, A., Castiello, U., Begliomini, C., 2019. The impulsive brain: Neural underpinnings of binge eating behavior in normal-weight adults. Appetite 136, 33 49. https://doi.org/10.1016/j.appet.2018.12.043

Oswald, K.D., Murdaugh, D.L., King, V.L., Boggiano, M.M., 2011. Motivation for palatable food despite consequences in an animal model of binge eating. Int. J. Eat. Disord. 44, 203211. https://doi.org/10.1002/eat.20808

Parkes, S.L., Furlong, T.M., Black, A.D., Balleine, B.W., 2017. Intermittent feeding alters sensitivity to changes in reward value. Appetite 113, 1-6. https://doi.org/https://doi.org/10.1016/j.appet.2017.02.009

Patton, J.H., Stanford, M.S., Barratt, E.S., 1995. Factor structure of the Barratt impulsiveness scale. J. Clin. Psychol. 51, 768-74.

Popien, A., Frayn, M., von Ranson, K.M., Sears, C.R., 2015. Eye gaze tracking reveals heightened attention to food in adults with binge eating when viewing images of real-world scenes. Appetite 91, 233-240. https://doi.org/https://doi.org/10.1016/j.appet.2015.04.046

Preuss, H., Leister, L., Pinnow, M., Legenbauer, T., 2019. Inhibitory control pathway to disinhibited eating: A matter of perspective? Appetite 141, 104297. https://doi.org/https://doi.org/10.1016/j.appet.2019.05.028 
Racine, S.E., Burt, S.A., Keel, P.K., Sisk, C.L., Neale, M.C., Boker, S., Klump, K.L., 2015. Examining associations between negative urgency and key components of objective binge episodes. Int. J. Eat. Disord. 48, 527-531. https://doi.org/10.1002/eat.22412

Racine, S.E., VanHuysse, J.L., Keel, P.K., Burt, S.A., Neale, M.C., Boker, S., Klump, K.L., 2017. Eating disorder-specific risk factors moderate the relationship between negative urgency and binge eating: A behavioral genetic investigation. J. Abnorm. Psychol. 126, 481-494. https://doi.org/10.1037/abn0000204

Ralph-Nearman, C., Stewart, J.L., Jones, K.A., 2020. The role of negative urgency in risky alcohol drinking and binge-eating in United Kingdom male and female students. Addict. Behav. Reports 11, 100274. https://doi.org/https://doi.org/10.1016/j.abrep.2020.100274

Reas, D.L., Grilo, C.M., 2015. Pharmacological treatment of binge eating disorder: update review and synthesis. Expert Opin. Pharmacother. 16, 1463-1478. https://doi.org/10.1517/14656566.2015.1053465

Reitan, R.M., 1958. Validity of the Trail Making Test as an Indicator of Organic Brain Damage. Percept. Mot. Skills 8, 271-276. https://doi.org/10.2466/pms.1958.8.3.271

Reitan, R.M., 1955. The relation of the Trail Making Test to organic brain damage. J. Consult. Psychol. 19, 393-394. https://doi.org/10.1037/h0044509

Reiter, A.M.F., Heinze, H.J., Schlagenhauf, F., Deserno, L., 2017. Impaired Flexible RewardBased Decision-Making in Binge Eating Disorder: Evidence from Computational Modeling and Functional Neuroimaging. Neuropsychopharmacology 42, 628-637. https://doi.org/10.1038/npp.2016.95

Reynolds, B., Ortengren, A., Richards, J.B., de Wit, H., 2006. Dimensions of impulsive behavior: Personality and behavioral measures. Pers. Individ. Dif. 40, 305-315. 
https://doi.org/https://doi.org/10.1016/j.paid.2005.03.024

Robles, E., Vargas, P.A., 2007. Functional parameters of delay discounting assessment tasks: Order of presentation. Behav. Processes 75, 237-241. https://doi.org/https://doi.org/10.1016/j.beproc.2007.02.014

Rogers, R.D., Everitt, B.J., Baldacchino, A., Blackshaw, A.J., Swainson, R., Wynne, K., Baker, N.B., Hunter, J., Carthy, T., Booker, E., London, M., Deakin, J.F.W., Sahakian, B.J., Robbins, T.W., 1999. Dissociable Deficits in the Decision-Making Cognition of Chronic Amphetamine Abusers, Opiate Abusers, Patients with Focal Damage to Prefrontal Cortex, and Tryptophan-Depleted Normal Volunteers: Evidence for Monoaminergic Mechanisms. Neuropsychopharmacology 20, 322-339. https://doi.org/10.1016/S0893$133 \times(98) 00091-8$

Rosenberg, N., Bloch, M., Ben Avi, I., Rouach, V., Schreiber, S., Stern, N., Greenman, Y., 2013. Cortisol response and desire to binge following psychological stress: Comparison between obese subjects with and without binge eating disorder. Psychiatry Res. 208, 156-161. https://doi.org/https://doi.org/10.1016/j.psychres.2012.09.050

Rossetti, C., Spena, G., Halfon, O., Boutrel, B., 2014. Evidence for a compulsive-like behavior in rats exposed to alternate access to highly preferred palatable food. Addict. Biol. 19, 975-985. https://doi.org/10.1111/adb.12065

Rubia, K., Halari, R., Christakou, A., Taylor, E., 2009. Impulsiveness as a timing disturbance: neurocognitive abnormalities in attention-deficit hyperactivity disorder during temporal processes and normalization with methylphenidate. Philos. Trans. R. Soc. Lond. B. Biol. Sci. 364, 1919-1931. https://doi.org/10.1098/rstb.2009.0014

Schäfer, A., Vaitl, D., Schienle, A., 2010. Regional grey matter volume abnormalities in bulimia nervosa and binge-eating disorder. Neuroimage 50, 639-643. 
https://doi.org/10.1016/j.neuroimage.2009.12.063

Schag, K., Rauch-Schmidt, M., Wernz, F., Zipfel, S., Batra, A., Giel, K.E., 2019. Transdiagnostic Investigation of Impulsivity in Alcohol Use Disorder and Binge Eating Disorder With Eye-Tracking Methodology-A Pilot Study. Front. psychiatry 10, 724. https://doi.org/10.3389/fpsyt.2019.00724

Schag, K., Teufel, M., Junne, F., Preissl, H., Hautzinger, M., Zipfel, S., Giel, K.E., 2013. Impulsivity in Binge Eating Disorder: Food Cues Elicit Increased Reward Responses and Disinhibition. PLoS One 8, e76542.

Schmidt, R., Lüthold, P., Kittel, R., Tetzlaff, A., Hilbert, A., 2016. Visual attentional bias for food in adolescents with binge-eating disorder. J. Psychiatr. Res. 80, 22-29. https://doi.org/10.1016/j.jpsychires.2016.05.016

Schmitz, F., Naumann, E., Biehl, S., Svaldi, J., 2015. Gating of attention towards food stimuli in binge eating disorder. Appetite 95, 368-374. https://doi.org/10.1016/j.appet.2015.07.023

Schmitz, F., Naumann, E., Trentowska, M., Svaldi, J., 2014. Attentional bias for food cues in binge eating disorder. Appetite 80, 70-80. https://doi.org/https://doi.org/10.1016/j.appet.2014.04.023

Schulz, S., Laessle, R.G., 2012. Stress-induced laboratory eating behavior in obese women with binge eating disorder. Appetite 58, 457-461. https://doi.org/https://doi.org/10.1016/j.appet.2011.12.007

Serra, R., Kiekens, G., Vanderlinden, J., Vrieze, E., Auerbach, R.P., Benjet, C., Claes, L., Cuijpers, P., Demyttenaere, K., Ebert, D.D., Tarsitani, L., Green, J.G., Kessler, R.C., Nock, M.K., Mortier, P., Bruffaerts, R., 2020. Binge eating and purging in first-year college 
students: Prevalence, psychiatric comorbidity, and academic performance. Int. J. Eat. Disord. 53, 339-348. https://doi.org/10.1002/eat.23211

Smith, D.G., Robbins, T.W., 2013. The Neurobiological Underpinnings of Obesity and Binge Eating: A Rationale for Adopting the Food Addiction Model. Biol. Psychiatry 73, 804-810. https://doi.org/10.1016/j.biopsych.2012.08.026

Sperling, I., Baldofski, S., Luthold, P., Hilbert, A., 2017. Cognitive Food Processing in BingeEating Disorder: An Eye-Tracking Study. Nutrients 9. https://doi.org/10.3390/nu9080903

Spurrell, E.B., Wilfley, D.E., Tanofsky, M.B., Brownell, K.D., 1997. Age of onset for binge eating: Are there different pathways to binge eating? Int. J. Eat. Disord. 21, 55-65. https://doi.org/10.1002/(SICI)1098-108X(199701)21:1<55::AID-EAT7>3.0.CO;2-2

Stahl, C., Voss, A., Schmitz, F., Nuszbaum, M., Tüscher, O., Lieb, K., Klauer, K.C., 2014. Behavioral components of impulsivity. J. Exp. Psychol. Gen. 143, 850.

Steward, T., Mestre-Bach, G., Vintro-Alcaraz, C., Aguera, Z., Jimenez-Murcia, S., Granero, R., Fernandez-Aranda, F., 2017. Delay Discounting of Reward and Impulsivity in Eating Disorders: From Anorexia Nervosa to Binge Eating Disorder. Eur. Eat. Disord. Rev. 25, 601-606. https://doi.org/10.1002/erv.2543

Stroop, J.R., 1935. Studies of interference in serial verbal reactions. J. Exp. Psychol. 18, 643.

Svaldi, J., Brand, M., Tuschen-Caffier, B., 2010. Decision-making impairments in women with binge eating disorder. Appetite 54, 84-92.

Svaldi, J., Naumann, E., Trentowska, M., Schmitz, F., 2014a. General and food-specific inhibitory deficits in binge eating disorder. Int. J. Eat. Disord. 47, 534-542. https://doi.org/10.1002/eat.22260 
Svaldi, J., Schmitz, F., Trentowska, M., Tuschen-Caffier, B., Berking, M., Naumann, E., 2014b. Cognitive interference and a food-related memory bias in binge eating disorder. Appetite 72, 28-36. https://doi.org/10.1016/j.appet.2013.09.014

Tanofsky-Kraff, M., Cohen, M.L., Yanovski, S.Z., Cox, C., Theim, K.R., Keil, M., Reynolds, J.C., Yanovski, J.A., 2006. A Prospective Study of Psychological Predictors of Body Fat Gain Among Children at High Risk for Adult Obesity. Pediatrics 117, 1203 LP - 1209.

Thornton, L.M., Watson, H.J., Jangmo, A., Welch, E., Wiklund, C., von Hausswolff-Juhlin, Y., Norring, C., Herman, B.K., Larsson, H., Bulik, C.M., 2017. Binge-eating disorder in the Swedish national registers: Somatic comorbidity. Int. J. Eat. Disord. 50, 58-65. https://doi.org/10.1002/eat.22624

Tiego, J., Oostermeijer, S., Prochazkova, L., Parkes, L., Dawson, A., Youssef, G., Oldenhof, E., Carter, A., Segrave, R.A., Fontenelle, L.F., Yücel, M., 2019. Overlapping dimensional phenotypes of impulsivity and compulsivity explain co-occurrence of addictive and $\begin{array}{llll}\text { related behaviors. } & \text { CNS }\end{array}$ https://doi.org/10.1017/S1092852918001244

Udo, T., Grilo, C.M., 2018. Prevalence and Correlates of DSM-5-Defined Eating Disorders in a Nationally Representative Sample of U.S. Adults. Biol. Psychiatry 84, 345-354. https://doi.org/10.1016/j.biopsych.2018.03.014

Velázquez-Sánchez, C., Ferragud, A., Moore, C.F., Everitt, B.J., Sabino, V., Cottone, P., 2014. High Trait Impulsivity Predicts Food Addiction-Like Behavior in the Rat. Neuropsychopharmacology 39, 2463-2472. https://doi.org/10.1038/npp.2014.98

Velázquez-Sánchez, C., Santos, J.W., Smith, K.L., Ferragud, A., Sabino, V., Cottone, P., 2015. Seeking behavior, place conditioning, and resistance to conditioned suppression of feeding in rats intermittently exposed to palatable food. Behav. Neurosci. 129, 219-224. 
https://doi.org/10.1037/bne0000042

Verbruggen, F., Logan, G.D., 2008a. Response inhibition in the stop-signal paradigm. Trends Cogn. Sci. 12, 418-424. https://doi.org/10.1016/j.tics.2008.07.005

Verbruggen, F., Logan, G.D., 2008b. Automatic and controlled response inhibition: associative learning in the go/no-go and stop-signal paradigms. J. Exp. Psychol. Gen. 137, 649-672. https://doi.org/10.1037/a0013170

Vickers, S.P., Goddard, S., Brammer, R.J., Hutson, P.H., Heal, D.J., 2017. Investigation of impulsivity in binge-eating rats in a delay-discounting task and its prevention by the damphetamine prodrug, lisdexamfetamine. J. Psychopharmacol. 31, 784-797. https://doi.org/10.1177/0269881117691672

Villarejo, C., Fernandez-Aranda, F., Jimenez-Murcia, S., Penas-Lledo, E., Granero, R., Penelo, E., Tinahones, F.J., Sancho, C., Vilarrasa, N., Montserrat-Gil de Bernabe, M., Casanueva, F.F., Fernandez-Real, J.M., Fruhbeck, G., De la Torre, R., Treasure, J., Botella, C., Menchon, J.M., 2012. Lifetime obesity in patients with eating disorders: increasing prevalence, clinical and personality correlates. Eur. Eat. Disord. Rev. 20, 250254. https://doi.org/10.1002/erv.2166

Voon, V., Derbyshire, K., Rück, C., Irvine, M.A., Worbe, Y., Enander, J., Schreiber, L.R.N., Gillan, C., Fineberg, N.A., Sahakian, B.J., 2015a. Disorders of compulsivity : a common bias towards learning habits 345-352. https://doi.org/https://doi.org/10.1038/mp.2014.44

Voon, V., Derbyshire, K., Rück, C., Irvine, M.A., Worbe, Y., Enander, J., Schreiber, L.R.N., Gillan, C., Fineberg, N.A., Sahakian, B.J., Robbins, T.W., Harrison, N.A., Wood, J., Daw, N.D., Dayan, P., Grant, J.E., Bullmore, E.T., 2015b. Disorders of compulsivity: a common bias towards learning habits. Mol. Psychiatry 20, 345-352. https://doi.org/10.1038/mp.2014.44 
Voon, V., Irvine, M.A., Derbyshire, K., Worbe, Y., Lange, I., Abbott, S., Morein-Zamir, S., Dudley, R., Caprioli, D., Harrison, N.A., Wood, J., Dalley, J.W., Bullmore, E.T., Grant, J.E., Robbins, T.W., 2014a. Measuring "waiting" impulsivity in substance addictions and binge eating disorder in a novel analogue of rodent serial reaction time task. Biol. Psychiatry 75, 148-155. https://doi.org/10.1016/j.biopsych.2013.05.013

Voon, V., Irvine, M.A., Derbyshire, K., Worbe, Y., Lange, I., Abbott, S., Morein-Zamir, S., Dudley, R., Caprioli, D., Harrison, N.A., Wood, J., Dalley, J.W., Bullmore, E.T., Grant, J.E., Robbins, T.W., 2014b. Measuring "waiting" impulsivity in substance addictions and binge eating disorder in a novel analogue of rodent serial reaction time task. Biol. Psychiatry 75, 148-55. https://doi.org/10.1016/j.biopsych.2013.05.013

Voon, V., Joutsa, J., Majuri, J., Baek, K., Nord, C.L., Arponen, E., Forsback, S., Kaasinen, V., 2020. The neurochemical substrates of habitual and goal-directed control. Transl. Psychiatry 10, 84. https://doi.org/10.1038/s41398-020-0762-5

Voon, V., Morris, L.S., Irvine, M.A., Ruck, C., Worbe, Y., Derbyshire, K., Rankov, V., Schreiber, L.R., Odlaug, B.L., Harrison, N.A., Wood, J., Robbins, T.W., Bullmore, E.T., Grant, J.E., 2015c. Risk-taking in disorders of natural and drug rewards: neural correlates and effects of probability, valence, and magnitude. Neuropsychopharmacology 40, 804-812. https://doi.org/10.1038/npp.2014.242

Wang, G.-J., Geliebter, A., Volkow, N.D., Telang, F.W., Logan, J., Jayne, M.C., Galanti, K., Selig, P.A., Han, H., Zhu, W., Wong, C.T., Fowler, J.S., 2011. Enhanced Striatal Dopamine Release During Food Stimulation in Binge Eating Disorder. Obesity (Silver Spring). 19, 1601-1608. https://doi.org/10.1038/oby.2011.27

Welch, E., Jangmo, A., Thornton, L.M., Norring, C., von Hausswolff-Juhlin, Y., Herman, B.K., Pawaskar, M., Larsson, H., Bulik, C.M., 2016. Treatment-seeking patients with binge- 
eating disorder in the Swedish national registers: clinical course and psychiatric comorbidity. BMC Psychiatry 16, 163. https://doi.org/10.1186/s12888-016-0840-7

Wells, G.A., Shea, B., O'Connell, D. al, Peterson, J., Welch, V., Losos, M., Tugwell, P., 2021. The Newcastle-Ottawa Scale (NOS) for assessing the quality of nonrandomised studies $\begin{array}{llll}\text { in meta-analyses } & \text { [WWW } & \text { Document]. URL }\end{array}$ http://www.ohri.ca/programs/clinical_epidemiology/nos_manual.pdf (accessed 5.3.21).

Westermann, R., Spies, K., Stahl, G., Hesse, F.W., 1996. Relative effectiveness and validity of mood induction procedures: a meta-analysis. Eur. J. Soc. Psychol. 26, 557-580. https://doi.org/https://doi.org/10.1002/(SICI)1099-0992(199607)26:4<557::AIDEJSP769>3.0.CO;2-4

Whiteside, S.P., Lynam, D.R., 2001. The Five Factor Model and impulsivity: using a structural model of personality to understand impulsivity. Pers. Individ. Dif. 30, 669-689. https://doi.org/10.1016/S0191-8869(00)00064-7

Wilson, B.A., Alderman, N., Burgess, P.W., Emslie, H., Evans, J.J., 1996. BADS: Behavioral assessment of the dysexecutive syndrome. Pearson.

Wu, M., Giel, K.E., Skunde, M., Schag, K., Rudofsky, G., de Zwaan, M., Zipfel, S., Herzog, W., Friederich, H.-C., 2013. Inhibitory control and decision making under risk in bulimia nervosa and binge-eating disorder. Int. J. Eat. Disord. 46, 721-728. https://doi.org/10.1002/eat.22143

Yan, W.-S., Zhang, R.-R., Lan, Y., Li, Z.-M., Li, Y.-H., 2018. Questionnaire-Based Maladaptive Decision-Coping Patterns Involved in Binge Eating Among 1013 College Students. Front. Psychol. 9, 609. https://doi.org/10.3389/fpsyg.2018.00609

Yanovski, S.Z., Nelson, J.E., Dubbert, B.K., Spitzer, R.L., 1993. Association of binge eating 
disorder and psychiatric comorbidity in obese subjects. Am. J. Psychiatry 150, 14721479. https://doi.org/10.1176/ajp.150.10.1472

Ziauddeen, H., Fletcher, P.C., 2013. Is food addiction a valid and useful concept? Obes. Rev. 14, 19-28. https://doi.org/10.1111/j.1467-789X.2012.01046.x 


\section{Abbreviations}

BED

Binge Eating Disorder

BE

Binge Eating

LOC

Loss of Control

NW

Normal Weight

OW Overweight/Obese

BEP Binge Eating Prone

BER Binge Eating Resistant

SCID Structured Clinical Interview for the diagnoses based on the diagnostic and statistical manual (DSM)

MINI Mini-International Neuropsychiatric Interview

DIPS Diagnostisches Interview bei psychischen Störungen

MIDI Minnesota Impulse control Disorders Interview

EDE-Q Eating Disorder Examination Questionnaire

EDDS Eating Disorder Diagnostic Scale

BES Binge Eating Scale

EAT-26 Eating Attitudes Test 


\section{Tables}

Table 1. Characteristics of studies investigating choice impulsivity/delay and probability discounting in humans (A) and animals (B).

\begin{tabular}{|c|c|c|c|c|c|c|c|c|c|c|c|}
\hline A. & Authors & Year & Group & $\begin{array}{l}\text { Ascertain- } \\
\text { ment }\end{array}$ & $\mathrm{N}$ & $\mathrm{BMI}(\mathrm{M} \pm \mathrm{SD})$ & Age $(\mathrm{M} \pm \mathrm{SD})$ & Gender & Paradigm & Main Finding & $\begin{array}{l}\text { NOS } \\
\text { Score }\end{array}$ \\
\hline & \multirow[t]{3}{*}{ Manwaring et al. } & \multirow[t]{3}{*}{2011} & BED & \multirow[t]{3}{*}{$\star$} & 30 & $42.0 \pm 9.2$ & $49.5 \pm 9.6$ & \multirow[t]{3}{*}{ \% } & \multirow{3}{*}{$\begin{array}{l}\text { Delay and probabilistic } \\
\text { discounting task }\end{array}$} & \multirow[t]{3}{*}{$\mathrm{BED}>\mathrm{OW}=/>\mathrm{NW}$} & \multirow[t]{3}{*}{6} \\
\hline & & & OW & & 30 & $42.6 \pm 7.9$ & $48.8 \pm 9.6$ & & & & \\
\hline & & & NW & & 30 & $23.3 \pm 2.4$ & $43.8 \pm 12.4$ & & & & \\
\hline & \multirow[t]{3}{*}{ Davis, Patte et al. } & \multirow[t]{3}{*}{2010} & BED & \multirow[t]{3}{*}{ 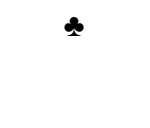 } & 65 & $35.7 \pm 9.0$ & $34.3 \pm 6.5$ & \multirow[t]{3}{*}{ \% } & \multirow[t]{3}{*}{ Delay Discounting Task } & \multirow[t]{3}{*}{$\mathrm{BED}>\mathrm{NW}, \mathrm{BED}=\mathrm{OW}$} & \multirow[t]{3}{*}{5} \\
\hline & & & OW & & 73 & $38.6 \pm 7.2$ & $35.2 \pm 6.7$ & & & & \\
\hline & & & NW & & 71 & $21.7 \pm 1.9$ & $31.8 \pm 6.3$ & & & & \\
\hline & \multirow[t]{4}{*}{ Blume, Schmidt et al. } & \multirow[t]{4}{*}{2019} & BED FA- & \multirow[t]{4}{*}{$\star$} & 19 & $41.9 \pm 5.3$ & $38.8 \pm 9.4$ & \multirow[t]{4}{*}{$\Phi^{\pi}$} & \multirow[t]{4}{*}{ Delay Discounting Task } & \multirow{4}{*}{$\begin{array}{l}\mathrm{OW}(\mathrm{FA}+)>\mathrm{BED}(\mathrm{FA}+)=\mathrm{BED}(\mathrm{FA}- \\
)=\mathrm{OW}\left(\mathrm{FA}^{-}\right)\end{array}$} & \multirow[t]{4}{*}{5} \\
\hline & & & $\mathrm{BED} \mathrm{FA}+$ & & 23 & $42.2 \pm 6.1$ & $37.5 \pm 10.1$ & & & & \\
\hline & & & OW FA- & & 23 & $42.8 \pm 4.8$ & $40.5 \pm 10.9$ & & & & \\
\hline & & & OW FA+ & & 23 & $44.1 \pm 6.6$ & $43.4 \pm 10.4$ & & & & \\
\hline & \multirow{2}{*}{$\begin{array}{l}\text { Manasse, Forman et } \\
\text { al. }\end{array}$} & \multirow[t]{2}{*}{2015} & BED & \multirow[t]{2}{*}{$\star$} & 31 & $36.8 \pm 8.0$ & $45.1 \pm 14.9$ & \multirow[t]{2}{*}{ Q } & \multirow[t]{2}{*}{ Delay Discounting Task } & \multirow[t]{2}{*}{$\mathrm{BED}>\mathrm{OW}$} & \multirow[t]{2}{*}{6} \\
\hline & & & OW & & 43 & $37.9 \pm 6.3$ & $51.1 \pm 8.3$ & & & & \\
\hline & \multirow[t]{2}{*}{$\begin{array}{l}\text { Bartholdy, Rennalls } \\
\text { et al. }\end{array}$} & \multirow[t]{2}{*}{2017} & BED & & 11 & $28.9 \pm 6.9$ & $28.7 \pm 11.2$ & Q & $\begin{array}{l}\text { Monetary Temporal } \\
\text { Discounting Task }\end{array}$ & $\mathrm{BED}=\mathrm{NW}$ & 6 \\
\hline & & & NW & & 28 & $22.0 \pm 2.0$ & $24.6 \pm 5.1$ & & & & \\
\hline & $\begin{array}{l}\text { Steward, Mestre- } \\
\text { Bach et al }\end{array}$ & 2017 & BED & 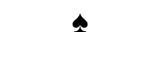 & 24 & $38.9 \pm 9.7$ & $33.6 \pm 8.6$ & Q & Monetary Choice Questionnaire & $\mathrm{BED}>\mathrm{NW}$ & 4 \\
\hline & & & NW & & 80 & $21.6 \pm 3.2$ & $23.0 \pm 4.4$ & & & & \\
\hline & Mole, Irvine et al & 2015 & BED & 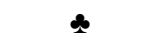 & 30 & $34.7 \pm 5.5$ & $42.9 \pm 6.6$ & $\Phi^{\pi}$ & Monetary Choice Questionnaire & $\mathrm{BED}, \mathrm{OW}>\mathrm{NW}$ & 4 \\
\hline & & & OW & & 30 & $32.7 \pm 3.4$ & $44.1 \pm 9.7$ & & & & \\
\hline & & & NW & & 30 & $23.9 \pm 2.7$ & $44.0 \pm 10.9$ & & & & \\
\hline & Yan, Zhang et al. & 2018 & $\mathrm{BE}$ & $\bullet$ & 85 & $21.0 \pm 2.6$ & $18.8 \pm 0.9$ & $\Phi^{\pi}$ & Monetary Choice Questionnaire & $\mathrm{BE}=\mathrm{NW}$ & 6 \\
\hline & & & NW & & 928 & $20.7 \pm 3.2$ & $18.9 \pm 0.8$ & & \& Probabilistic discounting task & & \\
\hline B. & Authors & Year & Group & & $\mathrm{N}$ & Species & & Sex & Paradigm & Main Finding & \\
\hline
\end{tabular}




\begin{tabular}{|c|c|c|c|c|c|c|c|}
\hline \multirow{2}{*}{$\begin{array}{l}\text { Vickers, Goddard et } \\
\text { al. }\end{array}$} & \multirow[b]{2}{*}{2017} & BER & \multicolumn{2}{|l|}{6} & \multirow[b]{2}{*}{ 우 } & \multirow[b]{2}{*}{ Delay discounting task } & \multirow[b]{2}{*}{$\mathrm{BE}>\mathrm{CON}$} \\
\hline & & $\mathrm{BE}$ & 12 & Rats & & & \\
\hline Moore Blasio et & 2018 & $\mathrm{CON}$ & $\begin{array}{l}6 \\
29\end{array}$ & Rats & $0^{\pi}$ & Delay discountino task & $\mathrm{BF}-\mathrm{CON}$ \\
\hline Mioore, Dldsto el al. & 2010 & $\begin{array}{l}\mathrm{DL} \\
\mathrm{CON}\end{array}$ & $\begin{array}{l}22 \\
21\end{array}$ & Kats & $\sigma^{\prime}$ & Delay discounting task & $\mathrm{DL}=\mathrm{CON}$ \\
\hline
\end{tabular}

$\mathrm{BE}(\mathrm{D})$ - Binge eating (disorder), OW - overweight/obese, NW - normal weight, FA - food addiction, BEP - binge eating prone, BER - binge eating resistant, CON - control, $\star$ -

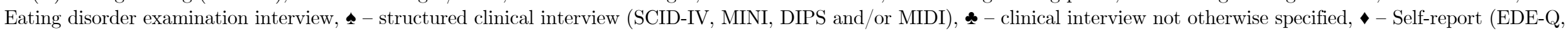
EDDS, BES, EAT26), NOS - Newcastle-Ottawa Scale.

Table 2. Characteristics of studies investigating decision-making under risk/uncertainty in humans

\begin{tabular}{|c|c|c|c|c|c|c|c|c|c|c|c|}
\hline A. & Authors & Year & Group & $\begin{array}{l}\text { Ascertain- } \\
\text { ment }\end{array}$ & $\mathrm{N}$ & $\mathrm{BMI}(\mathrm{M} \pm \mathrm{SD})$ & Age $(\mathrm{M} \pm \mathrm{SD})$ & Gender & Paradigm & Main Finding & $\begin{array}{l}\text { NOS } \\
\text { Score }\end{array}$ \\
\hline \multirow{2}{*}{\multicolumn{2}{|c|}{$\begin{array}{l}\text { Manasse, Forman et } \\
\text { al. }\end{array}$}} & \multirow[t]{2}{*}{2015} & BED & \multirow[t]{2}{*}{$\star$} & 31 & $36.8 \pm 8.0$ & $45.1 \pm 14.9$ & \multirow[t]{2}{*}{ 웅 } & \multirow[t]{2}{*}{ Balloon Analogue Risk Task } & \multirow[t]{2}{*}{$\mathrm{BED}=\mathrm{OW}$} & \multirow[t]{2}{*}{6} \\
\hline & & & OW & & 43 & $37.9 \pm 6.3$ & $51.1 \pm 8.3$ & & & & \\
\hline \multirow{2}{*}{\multicolumn{2}{|c|}{ Danner, Evers et al. }} & \multirow[t]{2}{*}{2013} & BED & \multirow[t]{2}{*}{2} & 31 & $37.5 \pm 5.1$ & $38.5 \pm 10.7$ & \multirow[t]{2}{*}{ Q } & \multirow[t]{2}{*}{ Iowa Gambling Task (adapted) } & \multirow{2}{*}{$\begin{array}{l}\mathrm{BED}>\mathrm{NW} \text { disadvantageous decks } \\
\text { after punishments \& after negative } \\
\text { mood induction }\end{array}$} & \multirow[t]{2}{*}{3} \\
\hline & & & NW & & 34 & $21.8 \pm 2.3$ & $30.2 \pm 14.5$ & & & & \\
\hline \multirow{3}{*}{\multicolumn{2}{|c|}{$\begin{array}{l}\text { Kollei, Rustemeier et } \\
\text { al. }\end{array}$}} & \multirow[t]{3}{*}{2018} & BED & \multirow[t]{3}{*}{ 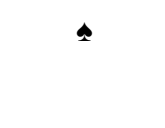 } & 48 & $43.3 \pm 6.3$ & $40.7 \pm 12.9$ & \multirow[t]{3}{*}{$\Phi^{\pi}$} & \multirow[t]{3}{*}{ Cambridge Gambling Task } & $\mathrm{BED}=\mathrm{NW}<\mathrm{OW}$ risk taking & \multirow[t]{3}{*}{6} \\
\hline & & & OW & & 48 & $43.6 \pm 7.2$ & $37.9 \pm 12.7$ & & & \multirow{2}{*}{$\begin{array}{l}\mathrm{BED}=\mathrm{OW}>\text { delay aversion, } \\
\text { deliberation time }\end{array}$} & \\
\hline & & & NW & & 48 & $22.1 \pm 1.9$ & $37.7 \pm 15.7$ & & & & \\
\hline & Grant \& & 2019 & BED & 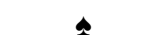 & 17 & $33.9 \pm 5.1$ & $25.5 \pm 4.8$ & $\Phi^{\pi}$ & Cambridge Gambling Task & $\mathrm{BED}=\mathrm{OW}=\mathrm{NW}$ & 6 \\
\hline & Chamberlain & & OW & & 17 & $31.4 \pm 6.3$ & $23.8 \pm 4.1$ & & & & \\
\hline \multirow{3}{*}{\multicolumn{2}{|c|}{ Preuss et al. }} & \multirow[t]{3}{*}{2019} & BED & $\star$ & 24 & $32.2 \pm 4.5$ & $37.4 \pm 12.1$ & \multirow[t]{3}{*}{$\Phi$} & \multirow[t]{3}{*}{ Door Opening Task } & \multirow[t]{3}{*}{$\mathrm{BED}=\mathrm{OW}=\mathrm{NW}$} & \multirow[t]{3}{*}{6} \\
\hline & & & OW & & 47 & $33.5 \pm 3.6$ & $38.1 \pm 10.0$ & & & & \\
\hline & & & NW & & 30 & $24.0 \pm 2.5$ & $36.3 \pm 12.1$ & & & & \\
\hline \multirow{2}{*}{\multicolumn{2}{|c|}{$\mathrm{Wu}$, Giel et al. }} & \multirow[t]{2}{*}{2013} & BED & 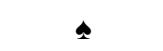 & 54 & $34.0 \pm 5.0$ & $40.1 \pm 11.6$ & \multirow[t]{2}{*}{$\Phi^{\pi}$} & \multirow[t]{2}{*}{ Game of Dice } & \multirow[t]{2}{*}{$\mathrm{BED}=\mathrm{OW}$} & 6 \\
\hline & & & OW & & 43 & $35.1 \pm 5.1$ & $39.8 \pm 11.3$ & & & & \\
\hline & Svaldi, Brand et al. & 2010 & BED & $\star$ & 17 & $32.8 \pm 3.5$ & $42.4 \pm 12.3$ & 우 & Game of Dice & $\mathrm{BED}>\mathrm{OW}$ risky choices & 6 \\
\hline & & & OW & & 18 & $30.7 \pm 3.9$ & $38.3 \pm 13.1$ & & & & \\
\hline & Davis, Patte et al. & 2010 & BED & م & 65 & $35.7 \pm 9.0$ & $34.3 \pm 6.5$ & 우 & Iowa Gambling Task & $\mathrm{BED}=\mathrm{OW}>\mathrm{NW}$ risky choices & 5 \\
\hline & & & OW & & 73 & $38.6 \pm 7.2$ & $35.2 \pm 6.7$ & & & & \\
\hline & & & NW & & 71 & $21.7 \pm 1.9$ & $31.8 \pm 6.3$ & & & & \\
\hline & Kittel, Schmidt et al. & 2017 & $\mathrm{BE}(\mathrm{D})$ & $\star$ & 22 & $99.2 \mathrm{nd} \pm 0.6$ & $14.9 \pm 2.2$ & $\Phi^{\pi}$ & Iowa Gambling Task & $\mathrm{BE}(\mathrm{D})=\mathrm{OW}=\mathrm{NW}$ & 6 \\
\hline & & & OW & & 22 & 98.9 th \pm 2.3 & $14.8 \pm 2.6$ & & & & \\
\hline
\end{tabular}




\begin{tabular}{|c|c|c|c|c|c|c|c|c|c|c|}
\hline \multirow{3}{*}{$\begin{array}{l}\text { Cordova, Schiavon et } \\
\text { al. }\end{array}$} & \multirow{3}{*}{2017} & NW & \multirow{3}{*}{$\bullet$} & 22 & 58.9 th \pm 24.0 & $15.2 \pm 2.4$ & \multirow{3}{*}{$\Phi^{\pi}$} & \multirow{3}{*}{ Iowa Gambling Task } & \multirow{3}{*}{$\mathrm{BE}<\mathrm{OW}$ performance } & \multirow{3}{*}{3} \\
\hline & & $\mathrm{BE}$ & & 18 & $37.3 \pm 6.1$ & $40.7 \pm 17.4$ & & & & \\
\hline & & OW & & 18 & $39.8 \pm 8.6$ & $49.5 \pm 14.8$ & & & & \\
\hline \multirow[t]{2}{*}{ Aloi, Rania et al. } & \multirow[t]{2}{*}{2015} & BED & s & 45 & $35.2 \pm 6.5$ & $30.6 \pm 10.9$ & \multirow[t]{2}{*}{ q } & \multirow[t]{2}{*}{ Iowa Gambling Task } & \multirow[t]{2}{*}{$\mathrm{BED}<\mathrm{NW}$ performance } & \multirow[t]{2}{*}{6} \\
\hline & & NW & & 45 & $20.2 \pm 1.6$ & $25.6 \pm 3.5$ & & & & \\
\hline \multirow[t]{2}{*}{ Müller, Brandl et al. } & \multirow[t]{2}{*}{2014} & BED & $\bullet$ & 34 & $46.7 \pm 9.0$ & $38.2 \pm 12.0$ & \multirow[t]{2}{*}{$\Phi^{\pi}$} & \multirow[t]{2}{*}{ Iowa Gambling Task } & \multirow[t]{2}{*}{$\mathrm{BE}<\mathrm{OW}$ performance } & \multirow[t]{2}{*}{5} \\
\hline & & OW & & 34 & $46.6 \pm 7.7$ & $38.5 \pm 11.9$ & & & & \\
\hline \multirow{3}{*}{$\begin{array}{l}\text { Danner, Ouwehand } \\
\text { et al. }\end{array}$} & \multirow[t]{3}{*}{2012} & BED & \& & 20 & $38.5 \pm 6.3$ & $38.1 \pm 11.0$ & \multirow[t]{3}{*}{ Q } & \multirow[t]{3}{*}{ Iowa Gambling Task } & \multirow{3}{*}{$\mathrm{BED}=\mathrm{OW}<\mathrm{NW}$ performance } & \multirow[t]{3}{*}{3} \\
\hline & & OW & & 21 & $30.8 \pm 3.0$ & $44.6 \pm 13.4$ & & & & \\
\hline & & NW & & 34 & $22.3 \pm 2.0$ & $36.1 \pm 14.1$ & & & & \\
\hline \multirow{3}{*}{$\begin{array}{l}\text { Dingemans, } \\
\text { Vanhaelen et al. }\end{array}$} & \multirow[t]{3}{*}{2019} & BED DEP- & $\star$ & 25 & $38.5 \pm 7.4$ & $32.8 \pm 8.5$ & \multirow[t]{3}{*}{$\Phi^{\pi}$} & \multirow[t]{3}{*}{ Iowa Gambling Task } & \multirow{3}{*}{$\mathrm{BED}(\mathrm{DEP}+)=\mathrm{BED}(\mathrm{DEP}-)=\mathrm{NW}$} & \multirow[t]{3}{*}{6} \\
\hline & & $\mathrm{BED} \mathrm{DEP}+$ & & 66 & $37.6 \pm 6.2$ & $34.2 \pm 9.9$ & & & & \\
\hline & & NW & & 56 & $23.5 \pm 2.8$ & $36.7 \pm 12.3$ & & & & \\
\hline \multirow[t]{4}{*}{ Blume, Schmidt et al. } & 2019 & BED FA- & $\star$ & 19 & $41.9 \pm 5.3$ & $38.8 \pm 9.4$ & $\oint^{\pi}$ & Iowa Gambling Task & $\mathrm{BED}(\mathrm{FA}+)=\mathrm{BED}(\mathrm{FA}-$ & 5 \\
\hline & & $\mathrm{BED} \mathrm{FA}+$ & & 23 & $42.2 \pm 6.1$ & $37.5 \pm 10.1$ & & & )$=\mathrm{OW}(\mathrm{FA}+)=\mathrm{OW}(\mathrm{FA}-)$ & \\
\hline & & OW FA- & & 23 & $42.8 \pm 4.8$ & $40.5 \pm 10.9$ & & & & \\
\hline & & $\mathrm{OW} \mathrm{FA}+$ & & 23 & $44.1 \pm 6.6$ & $43.4 \pm 10.4$ & & & & \\
\hline Aloi, Rania et al. & 2020 & BED & م & 35 & $38.9 \pm 6.9$ & $44.2 \pm 10.7$ & $\oint^{\pi}$ & Iowa Gambling Task & $\mathrm{BED}=\mathrm{OW}<\mathrm{NW}$ performance & 5 \\
\hline & & OW & & 32 & $36.4 \pm 6.8$ & $49.6 \pm 9.9$ & & & & \\
\hline & & NW & & 26 & $23.0 \pm 0.8$ & $46.7 \pm 11.1$ & & & & \\
\hline Voon, Morris et al. & 2014 & BED & * & 30 & $34.7 \pm 5.5$ & $42.9 \pm 6.6$ & $\Phi^{\pi}$ & Risky Jar Task & $\mathrm{BED}>\mathrm{NW}$ overweighting of & 5 \\
\hline & & OW & & 30 & $32.7 \pm 3.4$ & $44.1 \pm 9.7$ & & & probabilities & \\
\hline & & NW & & 30 & $23.0 \pm 2.7$ & $44.0 \pm 10.9$ & & & $\mathrm{BED}>\mathrm{NW}$ risk taking (reward) & \\
\hline
\end{tabular}

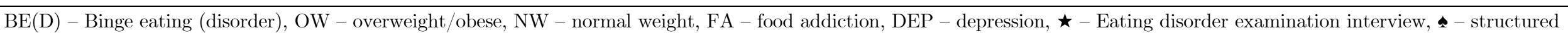

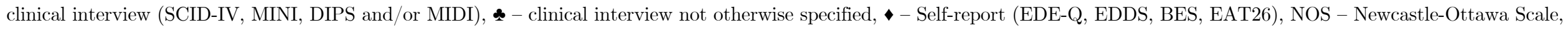
BMI summary statistics for Kittel, Schmidt et al. (2017) are in percentiles. 


\begin{tabular}{|c|c|c|c|c|c|c|c|c|c|c|c|}
\hline A. & Authors & Year & Group & $\begin{array}{l}\text { Ascertain- } \\
\text { ment }\end{array}$ & $\mathrm{N}$ & $\mathrm{BMI}(\mathrm{M} \pm \mathrm{SD})$ & Age $(\mathrm{M} \pm \mathrm{SD})$ & Gender & Paradigm & Main Finding & $\begin{array}{l}\text { NOS } \\
\text { Score }\end{array}$ \\
\hline & Mobbs, Iglesias et al. & 2011 & $\begin{array}{l}\text { BED } \\
\text { OW } \\
\text { NW }\end{array}$ & 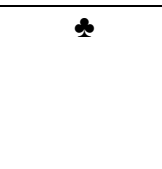 & $\begin{array}{l}16 \\
16 \\
16\end{array}$ & $\begin{array}{l}34.6 \pm 3.5 \\
33.6 \pm 6.4 \\
21.3 \pm 1.8\end{array}$ & $\begin{array}{l}45.1 \pm 12.1 \\
39.3 \pm 12.2 \\
40.2 \pm 11.3\end{array}$ & $\phi^{\pi}$ & $\begin{array}{l}\text { Food-Body Mental Flexibility } \\
\text { Task }\end{array}$ & $\begin{array}{l}\mathrm{BED}>\mathrm{OW}>\mathrm{NW} \text { comission errors } \\
\mathrm{BED}>\mathrm{OW}>\mathrm{NW} \text { omissions (food } \\
\text { context) } \mathrm{BED}=\mathrm{OW}>\mathrm{NW} \\
\text { omissions (other stimuli) }\end{array}$ & 5 \\
\hline & $\begin{array}{l}\text { Cordova, Schiavon et } \\
\text { al. }\end{array}$ & 2017 & $\begin{array}{l}\text { BED } \\
\text { OW }\end{array}$ & $\bullet$ & $\begin{array}{l}18 \\
18\end{array}$ & $\begin{array}{l}37.3 \pm 6.1 \\
39.8 \pm 8.6\end{array}$ & $\begin{array}{l}40.7 \pm 17.4 \\
49.5 \pm 14.8\end{array}$ & $\Phi^{\pi}$ & Go-NoGo Task & $\begin{array}{l}\mathrm{BED}>\mathrm{OW} \text { comission errors } \\
\mathrm{BED}=\mathrm{OW} \text { omissions }\end{array}$ & 3 \\
\hline & $\begin{array}{l}\text { Blume, Schmidt et } \\
\text { al. }\end{array}$ & 2019 & $\begin{array}{l}\text { BED FA- } \\
\text { BED FA+ } \\
\text { OW FA- } \\
\text { OW FA+ }\end{array}$ & $\star$ & $\begin{array}{l}19 \\
23 \\
23 \\
23\end{array}$ & $\begin{array}{l}41.9 \pm 5.3 \\
42.2 \pm 6.1 \\
42.8 \pm 4.8 \\
44.1 \pm 6.6\end{array}$ & $\begin{array}{l}38.8 \pm 9.4 \\
37.5 \pm 10.1 \\
40.5 \pm 10.9 \\
43.4 \pm 10.4\end{array}$ & $\Phi$ & $\begin{array}{l}\mathrm{BED}(\mathrm{FA}+)=\mathrm{BED}(\mathrm{FA}- \\
)=\mathrm{OW}(\mathrm{FA}+)=\mathrm{OW}(\mathrm{FA}-) \\
\text { commissions }\end{array}$ & & 5 \\
\hline & Oliva, Morys et al. & 2019 & $\begin{array}{l}\mathrm{BE} \\
\mathrm{NW}\end{array}$ & $\bullet$ & $\begin{array}{l}21 \\
21\end{array}$ & $\begin{array}{l}22.3 \pm 2.1 \\
21.3 \pm 2.0\end{array}$ & $\begin{array}{l}23.9 \pm 3.2 \\
25.2 \pm 3.1\end{array}$ & $\phi^{\pi}$ & $\begin{array}{l}\text { Go-NoGo Task (food and non } \\
\text { food) }\end{array}$ & $\mathrm{BE}=\mathrm{NW}$ & 5 \\
\hline & $\begin{array}{l}\text { Antunes, Lorenzzi } \\
\text { Elkfury et al. }\end{array}$ & 2020 & $\begin{array}{l}\text { BED } \\
\text { OW } \\
\text { NW }\end{array}$ & 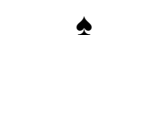 & $\begin{array}{l}13 \\
20 \\
14\end{array}$ & $\begin{array}{l}33.2 \pm 3.7 \\
33.1 \pm 4.0 \\
21.3 \pm 2.0\end{array}$ & $\begin{array}{l}26.4 \pm 4.3 \\
31.0 \pm 7.3 \\
32.2 \pm 7.9\end{array}$ & 우 & $\begin{array}{l}\text { Go-NoGo Task (food and non } \\
\text { food) }\end{array}$ & $\begin{array}{l}\mathrm{BED}=\mathrm{OW}=\mathrm{NW} \text { comission errors } \\
(\text { food and non-food })\end{array}$ & 5 \\
\hline & $\begin{array}{l}\text { Loeber, Rustemeier } \\
\text { et al. }\end{array}$ & 2018 & $\begin{array}{l}\text { BED } \\
\text { OW } \\
\text { NW }\end{array}$ & \& & $\begin{array}{l}17 \\
20 \\
20\end{array}$ & $\begin{array}{l}39.3 \pm 6.0 \\
33.2 \pm 3.2 \\
22.5 \pm 2.1\end{array}$ & $\begin{array}{l}26.5 \pm 3.5 \\
25.0 \pm 5.2 \\
23.6 \pm 2.0\end{array}$ & 우 & $\begin{array}{l}\text { Go-NoGo Task (food and non } \\
\text { food) }\end{array}$ & $\mathrm{BED}=\mathrm{OW}=\mathrm{NW}$ comission errors & 6 \\
\hline & Hege, Stingl et al. & 2015 & $\begin{array}{l}\text { BED } \\
\text { OW }\end{array}$ & 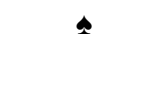 & $\begin{array}{l}17 \\
17\end{array}$ & $\begin{array}{l}36.5 \pm 4.9 \\
34.0 \pm 5.6\end{array}$ & $\begin{array}{l}41.4 \pm 12.3 \\
41.9 \pm 8.5\end{array}$ & 우 & $\begin{array}{l}\text { Go-NoGo Task (food and non } \\
\text { food) }\end{array}$ & $\begin{array}{l}\mathrm{BED}<\mathrm{OW} \text { performance NoGo } \\
\text { trials (food condition) }\end{array}$ & 5 \\
\hline & $\begin{array}{l}\text { Kollei, Rustemeier et } \\
\text { al. }\end{array}$ & 2018 & $\begin{array}{l}\text { BED } \\
\text { OW } \\
\text { NW }\end{array}$ & s & $\begin{array}{l}48 \\
48 \\
48\end{array}$ & $\begin{array}{l}43.3 \pm 6.3 \\
43.6 \pm 7.2 \\
22.1 \pm 1.9\end{array}$ & $\begin{array}{l}40.7 \pm 12.9 \\
37.9 \pm 12.7 \\
37.7 \pm 15.7\end{array}$ & $\Phi^{7}$ & Go-NoGo Task (food) & $\mathrm{BED}=\mathrm{OW}=\mathrm{NW}$ & 6 \\
\hline & Lyu, Zheng etal. & 2017 & $\begin{array}{l}\mathrm{BE} \\
\mathrm{NW}\end{array}$ & $\bullet$ & $\begin{array}{l}31 \\
31\end{array}$ & $\begin{array}{l}20.5 \pm 2.2 \\
19.6 \pm 2.1\end{array}$ & $\begin{array}{l}21.5 \pm 1.4 \\
21.4 \pm 1.5\end{array}$ & ㅇ & Go-NoGo Task (food) & $\begin{array}{l}\mathrm{BE}<\mathrm{NW} \text { performance high calorie } \\
\text { Go trials }\end{array}$ & 5 \\
\hline & Voon, Irvine et al. & 2014 & $\begin{array}{l}\text { BED } \\
\text { OW } \\
\text { NW }\end{array}$ & \& & $\begin{array}{l}30 \\
30 \\
30\end{array}$ & $\begin{array}{l}34.7 \pm 5.5 \\
32.7 \pm 3.4 \\
23.0 \pm 2.7\end{array}$ & $\begin{array}{l}42.9 \pm 6.6 \\
44.1 \pm 9.7 \\
44.0 \pm 10.9\end{array}$ & $\phi^{\pi}$ & Premature Response Task & $\mathrm{BED}=\mathrm{OW}=\mathrm{NW}$ & 5 \\
\hline & $\mathrm{Wu}$, Giel et al. & 2013 & $\begin{array}{l}\text { BED } \\
\text { OW }\end{array}$ & s. & $\begin{array}{l}54 \\
43\end{array}$ & $\begin{array}{l}34.0 \pm 5.0 \\
35.1 \pm 5.1\end{array}$ & $\begin{array}{l}40.1 \pm 11.6 \\
39.8 \pm 11.3\end{array}$ & $\Phi^{\pi}$ & $\begin{array}{l}\text { Stop Signal Reaction Time } \\
\text { Task }\end{array}$ & $\mathrm{BED}=\mathrm{OW}$ & 6 \\
\hline & Mole, Irvine et al & 2014 & $\begin{array}{l}\text { BED } \\
\text { OW } \\
\text { NW }\end{array}$ & 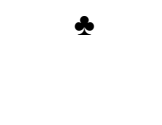 & $\begin{array}{l}30 \\
30 \\
30\end{array}$ & $\begin{array}{l}34.7 \pm 5.5 \\
32.7 \pm 3.4 \\
23.9 \pm 2.7\end{array}$ & $\begin{array}{l}42.9 \pm 6.6 \\
44.1 \pm 9.7 \\
44.0 \pm 10.9\end{array}$ & $\Phi^{\top}$ & $\begin{array}{l}\text { Stop Signal Reaction Time } \\
\text { Task }\end{array}$ & $\mathrm{BED}=\mathrm{NW}<\mathrm{OW}$ SSRT & 4 \\
\hline & Preuss et al. & 2019 & $\begin{array}{l}\text { BED } \\
\text { OW }\end{array}$ & $\star$ & $\begin{array}{l}24 \\
47\end{array}$ & $\begin{array}{l}32.2 \pm 4.5 \\
33.5 \pm 3.6\end{array}$ & $\begin{array}{l}37.4 \pm 12.1 \\
38.1 \pm 10.0\end{array}$ & $\Phi^{\top}$ & $\begin{array}{l}\text { Stop Signal Reaction Time } \\
\text { Task }\end{array}$ & $\mathrm{BED}>\mathrm{NW}=\mathrm{OW}$ SSRT & 6 \\
\hline
\end{tabular}




\begin{tabular}{|c|c|c|c|c|c|c|c|c|c|c|}
\hline & & NW & & 30 & $24.0 \pm 2.5$ & $36.3 \pm 12.1$ & & & & \\
\hline Grant \& & 2019 & BED & 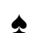 & 17 & $33.9 \pm 5.1$ & $25.5 \pm 4.8$ & $\Phi^{\pi}$ & Stop Signal Reaction Time & $\mathrm{BED}>\mathrm{NW}=\mathrm{OW}$ SSRT & 6 \\
\hline Chamberlain & & OW & & 17 & $31.4 \pm 6.3$ & $23.8 \pm 4.1$ & & Task & & \\
\hline \multirow{2}{*}{$\begin{array}{l}\text { Bartholdy, Rennalls } \\
\text { et al. }\end{array}$} & $2017 b$ & BED & 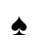 & 11 & $28.9 \pm 6.9$ & $28.7 \pm 11.2$ & ㅇ & Stop Signal Reaction Time & $\mathrm{BED}=\mathrm{NW}$ & 6 \\
\hline & & NW & & 28 & $22.0 \pm 2.0$ & $24.6 \pm 5.1$ & & Task & & \\
\hline \multirow[t]{2}{*}{ Oliva, Morys et al. } & 2019 & $\mathrm{BE}$ & $\bullet$ & 21 & $22.3 \pm 2.1$ & $23.9 \pm 3.2$ & $\Phi^{7}$ & Stop Signal Reaction Time & $\mathrm{BE}=\mathrm{NW}$ commission errors & 5 \\
\hline & & NW & & 21 & $21.3 \pm 2.0$ & $25.2 \pm 3.1$ & & Task (food and non-food) & & \\
\hline \multirow{4}{*}{$\begin{array}{l}\text { Svaldi, Naumann et } \\
\text { al. } \\
\text { Manasse, Goldstein } \\
\text { et al. }\end{array}$} & 2014 & BED & $\star$ & 31 & $35.0 \pm 5.1$ & $45.5 \pm 12.8$ & $\Phi^{\pi}$ & Stop Signal Reaction Time & $\mathrm{BED}>\mathrm{OW}$ SSRT & 6 \\
\hline & & OW & & 29 & $32.0 \pm 6.0$ & $40.1 \pm 12.1$ & & Task (food and non-food) & & \\
\hline & 2016 & BED & $\star$ & 25 & $35.2 \pm 7.7$ & $45.1 \pm 14.9$ & O & Stop Signal Reaction Time & $\mathrm{BED}>\mathrm{OW}$ SSRT & 5 \\
\hline & & OW & & 65 & $36.7 \pm 5.5$ & $52.4 \pm 9.2$ & & Task (food and non-food) & & \\
\hline
\end{tabular}

$\mathrm{BE}(\mathrm{D})$ - Binge eating (disorder), OW - overweight/obese, NW - normal weight, FA - food addiction, $\star$ - Eating disorder examination interview, - structured clinical interview (SCID-IV, MINI, DIPS and/or MIDI), - clinical interview not otherwise specified, - Self-report (EDE-Q, EDDS, BES, EAT26), NOS - Newcastle-Ottawa Scale.

Table 4. Characteristics of studies investigating reflection impulsivity in humans.

\begin{tabular}{|c|c|c|c|c|c|c|c|c|c|c|c|}
\hline A. & Authors & Year & Group & $\begin{array}{l}\text { Ascertain- } \\
\text { ment }\end{array}$ & $\mathrm{N}$ & $\mathrm{BMI}(\mathrm{M} \pm \mathrm{SD})$ & Age $(\mathrm{M} \pm \mathrm{SD})$ & Gender & Paradigm & Main Finding & $\begin{array}{l}\text { NOS } \\
\text { Score }\end{array}$ \\
\hline & Mole, Irvine et al & 2014 & BED & 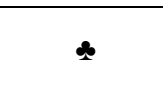 & 30 & $34.7 \pm 5.5$ & $42.9 \pm 6.6$ & $\Phi^{\pi}$ & Information Sampling Task & $\begin{array}{l}\mathrm{BED}=\mathrm{NW}>\mathrm{OW} \text { total points } \\
\mathrm{BED}=\mathrm{NW}<\mathrm{OW} \text { sampling errors }\end{array}$ & 4 \\
\hline & & & OW & & 30 & $32.7 \pm 3.4$ & $44.1 \pm 9.7$ & & & & \\
\hline & & & NW & & 30 & $23.9 \pm 2.7$ & $44.0 \pm 10.9$ & & & & \\
\hline
\end{tabular}


Table 5. Characteristics of studies investigating interference control in humans.

\begin{tabular}{|c|c|c|c|c|c|c|c|c|c|c|c|}
\hline A. & Authors & Year & Group & $\begin{array}{l}\text { Ascertain- } \\
\text { ment }\end{array}$ & $\mathrm{N}$ & $\mathrm{BMI}(\mathrm{M} \pm \mathrm{SD})$ & Age $(\mathrm{M} \pm \mathrm{SD})$ & Gender & Paradigm & Main Finding & $\begin{array}{l}\text { NOS } \\
\text { Score }\end{array}$ \\
\hline \multirow{3}{*}{\multicolumn{2}{|c|}{ Schag, Teufel et al. }} & \multirow[t]{3}{*}{2013} & $\mathrm{BE}(\mathrm{D})$ & \multirow[t]{3}{*}{ 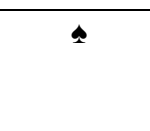 } & 25 & $35.4 \pm 5.6$ & $39.7 \pm 11.7$ & \multirow[t]{3}{*}{ q } & \multirow[t]{3}{*}{ Anti saccade task } & \multirow{3}{*}{$\begin{array}{l}\mathrm{BE}(\mathrm{D})>\mathrm{OW}=\mathrm{NW} \text { disengagement } \\
\text { (overall), particularly food on } \\
\text { second saccade }\end{array}$} & \multirow[t]{3}{*}{5} \\
\hline & & & OW & & 26 & $35.4 \pm 5.4$ & $39.9 \pm 12.6$ & & & & \\
\hline & & & NW & & 25 & $22.5 \pm 1.6$ & $39.4 \pm 11.8$ & & & & \\
\hline \multirow{3}{*}{\multicolumn{2}{|c|}{ Kittel, Schmidt et al. }} & \multirow[t]{3}{*}{2017} & $\mathrm{BE}(\mathrm{D})$ & $\star$ & 22 & $99.2 \mathrm{nd} \pm 0.6$ & $14.9 \pm 2.2$ & \multirow[t]{3}{*}{$\Phi^{\pi}$} & \multirow[t]{3}{*}{ Colour-Word-Interference Test } & \multirow{3}{*}{$\mathrm{BE}(\mathrm{D})=\mathrm{OW}>\mathrm{NW}$ completion time } & \multirow[t]{3}{*}{6} \\
\hline & & & OW & & 22 & 98.9 th \pm 2.3 & $14.8 \pm 2.6$ & & & & \\
\hline & & & NW & & 22 & 58.9 th \pm 24.0 & $15.2 \pm 2.4$ & & & & \\
\hline \multirow{4}{*}{\multicolumn{2}{|c|}{ Eneva et al. }} & \multirow[t]{4}{*}{2017} & BED OW & $\star$ & 32 & $34.2 \pm 0.8$ & $36.3 \pm 2.0$ & \multirow[t]{4}{*}{ Q } & \multirow{4}{*}{$\begin{array}{l}\text { D-KEFS Colour Word } \\
\text { Interference inhibition }\end{array}$} & \multirow[t]{4}{*}{$\mathrm{BED}(\mathrm{OW})=\mathrm{BED}(\mathrm{NW})=\mathrm{OW}=\mathrm{NW}$} & \multirow[t]{4}{*}{6} \\
\hline & & & BED NW & & 23 & $22.9 \pm 0.4$ & $23.3 \pm 0.7$ & & & & \\
\hline & & & OW & & 48 & $31.3 \pm 0.6$ & $38.0 \pm 1.8$ & & & & \\
\hline & & & NW & & 29 & $21.6 \pm 0.3$ & $24.5 \pm 1.2$ & & & & \\
\hline \multirow{2}{*}{\multicolumn{2}{|c|}{$\begin{array}{l}\text { Manasse, Forman et } \\
\text { al. }\end{array}$}} & \multirow[t]{2}{*}{2015} & BED & $\star$ & 31 & $36.8 \pm 8.0$ & $45.1 \pm 14.9$ & \multirow[t]{2}{*}{ 우 } & D-KEFS Colour Word & $\mathrm{BED}>\mathrm{OW} \mathrm{RT}$ & \multirow[t]{2}{*}{6} \\
\hline & & & OW & & 43 & $37.9 \pm 6.3$ & $51.1 \pm 8.3$ & & Interference inhibition & $\mathrm{BED}=\mathrm{OW}$ errors & \\
\hline \multirow{2}{*}{\multicolumn{2}{|c|}{ Lyu, Zheng et al. }} & \multirow[t]{2}{*}{2018} & $\mathrm{BE}$ & $\bullet$ & 31 & $21.0 \pm 0.5$ & $20.0 \pm 0.7$ & \multirow[t]{2}{*}{ 우 } & \multirow{2}{*}{ Flanker Task (Food) } & $\mathrm{BE}>\mathrm{NW}$ Flanker effect on RT & \multirow[t]{2}{*}{5} \\
\hline & & & NW & & 33 & $20.4 \pm 0.4$ & $21.2 \pm 0.3$ & & & NW $>$ BE RT for low calorie food & \\
\hline & Balodis, Molina et al. & 2013 & BED & s. & 11 & $37.1 \pm 3.9$ & $47.6 \pm 12.7$ & $\oint^{\pi}$ & Stroop Task & $\mathrm{BED}=\mathrm{OW}=\mathrm{NW}$ performance & 5 \\
\hline & & & OW & & 13 & $34.6 \pm 4.1$ & $35.4 \pm 9.3$ & & & & \\
\hline & & & NW & & 11 & $23.2 \pm 1.1$ & $32.7 \pm 11.3$ & & & & \\
\hline & Preuss et al. & 2019 & BED & $\star$ & 24 & $32.2 \pm 4.5$ & $37.4 \pm 12.1$ & $\Phi^{7}$ & Stroop Task (Food) & $\mathrm{BED}=\mathrm{OW}=\mathrm{NW} \mathrm{RT}$, interference & 6 \\
\hline & & & OW & & 47 & $33.5 \pm 3.6$ & $38.1 \pm 10.0$ & & & index & \\
\hline & & & NW & & 30 & $24.0 \pm 2.5$ & $36.3 \pm 12.1$ & & & & \\
\hline & Lee, Namkoong et al. & 2017 & BED & s. & 13 & $25.6 \pm 3.8$ & $23.6 \pm 2.6$ & 우 & Stroop Match to Sample (Food) & $\mathrm{BED}=\mathrm{NW}$ accuracy, $\mathrm{RT}$ & 5 \\
\hline & & & NW & & 14 & $20.4 \pm 2.6$ & $23.3 \pm 2.2$ & & & & \\
\hline & Svaldi, Schmitz et al. & 2014 & $\mathrm{BED}$ & $\star$ & 26 & $34.9 \pm 5.4$ & $46.1 \pm 14.6$ & 우 & N-Back with lures & $\mathrm{BED}>\mathrm{OW}$ errors and RT during & 6 \\
\hline & & & OW & & 31 & $33.6 \pm 6.4$ & $39.7 \pm 11.9$ & & & lure trials & \\
\hline & Eneva et al. & 2017 & BED OW & $\star$ & 32 & $34.2 \pm 0.8$ & $36.3 \pm 2.0$ & q & NIH Flanker Inhibitory Control & $\mathrm{BED}(\mathrm{OW})=\mathrm{BED}(\mathrm{NW})=\mathrm{OW}=\mathrm{NW}$ & 6 \\
\hline & & & BED NW & & 23 & $22.9 \pm 0.4$ & $23.3 \pm 0.7$ & & & & \\
\hline & & & OW & & 48 & $31.3 \pm 0.6$ & $38.0 \pm 1.8$ & & & & \\
\hline & & & NW & & 29 & $21.6 \pm 0.3$ & $24.5 \pm 1.2$ & & & & \\
\hline & Svaldi, Schmitz et al. & 2014 & BED & $\star$ & 31 & $35.14 \pm 5.1$ & $46.3 \pm 14.2$ & ㅇ & Recent Probes Task & $\mathrm{BED}=\mathrm{OW} / \mathrm{OB}$ accuracy & 6 \\
\hline & & & OW & & 36 & $33.31 \pm 6.2$ & $40.7 \pm 13.1$ & & & $\begin{array}{l}\mathrm{BED}>\mathrm{OW} / \mathrm{OB} \text { interference by } \\
\text { food stimuli }\end{array}$ & \\
\hline
\end{tabular}


$\mathrm{BE}(\mathrm{D})$ - Binge eating (disorder), OW - overweight/obese, NW - normal weight, FA - food addiction, $\star$ - Eating disorder examination interview, - structured clinical interview (SCID-IV, MINI, DIPS and/or MIDI), - clinical interview not otherwise specified, - Self-report (EDE-Q, EDDS, BES, EAT26), NOS - Newcastle-Ottawa Scale, BMI summary statistics for Kittel, Schmidt et al. (2017) are in percentiles. 
Table 6. Characteristics of studies investigating goal directed and habitual control in humans (A) and animals (B).

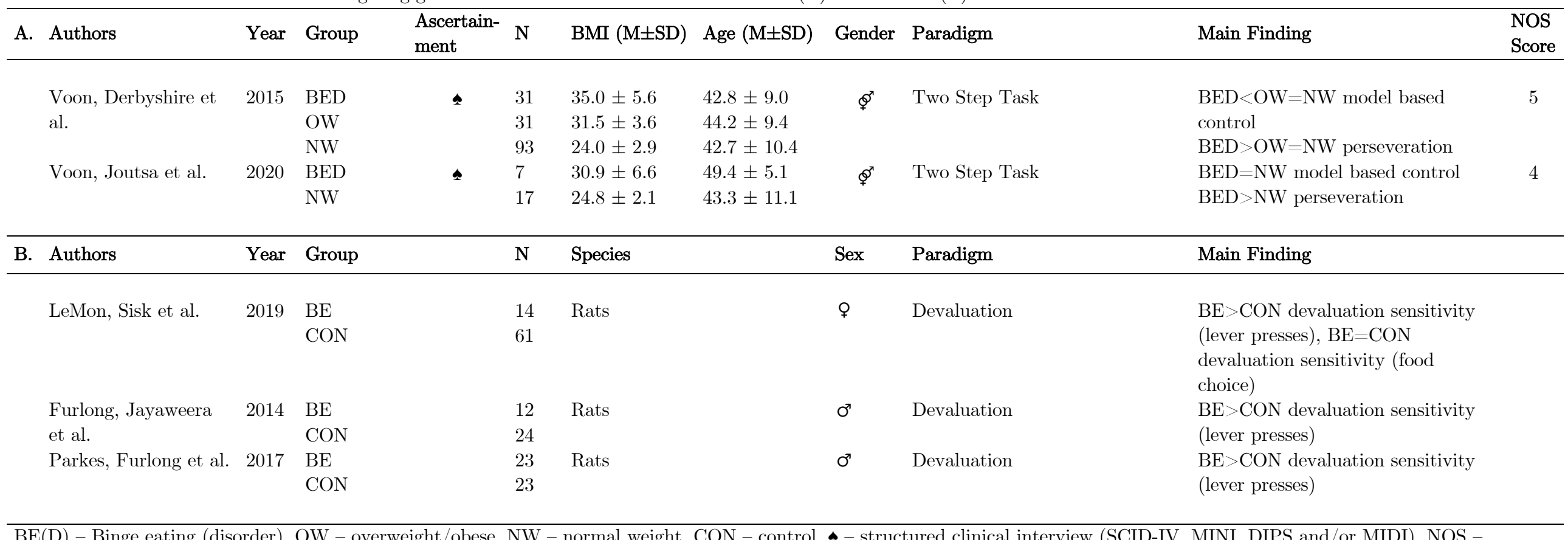

BE(D) - Binge eating (disorder), OW - overweight/obese, NW - normal weight, CON - control, - structured clinical interview (SCID-IV, MINI, DIPS and/or MIDI), NOS -

Newcastle-Ottawa Scale. 
Table 7. Characteristics of studies investigating cognitive flexibility in humans (A) and animals (B).

\begin{tabular}{|c|c|c|c|c|c|c|c|c|c|c|c|}
\hline A. & Authors & Year & Group & $\begin{array}{l}\text { Ascertain- } \\
\text { ment }\end{array}$ & $\mathrm{N}$ & $\mathrm{BMI}(\mathrm{M} \pm \mathrm{SD})$ & Age $(\mathrm{M} \pm \mathrm{SD})$ & Gender & Paradigm & Main Finding & $\begin{array}{l}\text { NOS } \\
\text { Score }\end{array}$ \\
\hline \multirow{2}{*}{\multicolumn{2}{|c|}{$\begin{array}{l}\text { Duchesne, Mattos et } \\
\text { al. }\end{array}$}} & \multirow[t]{2}{*}{2010} & BED & \multirow[t]{2}{*}{ 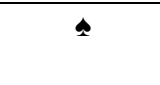 } & 38 & $35.9 \pm 2.9$ & $33.3 \pm 5.0$ & \multirow[t]{2}{*}{$\Phi^{\pi}$} & \multirow[t]{2}{*}{ BADS-Rule Shift Cards Test } & \multirow[t]{2}{*}{$\mathrm{BED}=\mathrm{OW}$} & \multirow[t]{2}{*}{5} \\
\hline & & & OW & & 38 & $36.6 \pm 3.8$ & $35.4 \pm 7.9$ & & & & \\
\hline \multirow{3}{*}{\multicolumn{2}{|c|}{ Kittel, Schmidt et al. }} & \multirow[t]{3}{*}{2017} & $\mathrm{BE}(\mathrm{D})$ & \multirow[t]{3}{*}{$\star$} & 22 & $99.2 \mathrm{nd} \pm 0.6$ & $14.9 \pm 2.2$ & \multirow{3}{*}{$\Phi^{\pi}$} & \multirow{3}{*}{$\begin{array}{l}\text { Comprehensive Trail Making } \\
\text { Test }\end{array}$} & \multirow[t]{3}{*}{$\mathrm{BE}(\mathrm{D})=\mathrm{OW}=\mathrm{NW}$} & \multirow[t]{3}{*}{6} \\
\hline & & & OW & & 22 & 98.9 th \pm 2.3 & $14.8 \pm 2.6$ & & & & \\
\hline & & & NW & & 22 & 58.9 th \pm 24.0 & $15.2 \pm 2.4$ & & & & \\
\hline \multirow{4}{*}{\multicolumn{2}{|c|}{ Eneva et al. }} & \multirow[t]{4}{*}{2017} & BED OW & \multirow[t]{4}{*}{$\star$} & 32 & $34.2 \pm 0.8$ & $36.3 \pm 2.0$ & \multirow[t]{4}{*}{ 우 } & \multirow{4}{*}{$\begin{array}{l}\text { D-KEFS trail-making number- } \\
\text { letter switching }\end{array}$} & \multirow[t]{4}{*}{$\mathrm{BED}(\mathrm{OW})=\mathrm{BED}(\mathrm{NW})=\mathrm{OW}=\mathrm{NW}$} & \multirow[t]{4}{*}{6} \\
\hline & & & BED NW & & 23 & $22.9 \pm 0.4$ & $23.3 \pm 0.7$ & & & & \\
\hline & & & OW & & 48 & $31.3 \pm 0.6$ & $38.0 \pm 1.8$ & & & & \\
\hline & & & NW & & 29 & $21.6 \pm 0.3$ & $24.5 \pm 1.2$ & & & & \\
\hline \multirow{4}{*}{\multicolumn{2}{|c|}{ Eneva et al. }} & \multirow[t]{4}{*}{2017} & BED OW & \multirow[t]{4}{*}{$\star$} & 32 & $34.2 \pm 0.8$ & $36.3 \pm 2.0$ & \multirow[t]{4}{*}{ o } & \multirow{4}{*}{$\begin{array}{l}\text { Dimensional Change Card Sort } \\
\text { Test }\end{array}$} & $\mathrm{BED}(\mathrm{OW})=\mathrm{BED}(\mathrm{NW})=\mathrm{OW}=\mathrm{NW}$ & 6 \\
\hline & & & BED NW & & 23 & $22.9 \pm 0.4$ & $23.3 \pm 0.7$ & & & & \\
\hline & & & OW & & 48 & $31.3 \pm 0.6$ & $38.0 \pm 1.8$ & & & & \\
\hline & & & NW & & 29 & $21.6 \pm 0.3$ & $24.5 \pm 1.2$ & & & & \\
\hline & Kollei, Rustemeier et & 2018 & BED & s & 48 & $43.3 \pm 6.3$ & $40.7 \pm 12.9$ & $\Phi^{\pi}$ & Intra-/Extradimensional set & $\mathrm{BED}=\mathrm{NW}=\mathrm{OW}$ & 6 \\
\hline & & & OW & & 48 & $43.6 \pm 7.2$ & $37.9 \pm 12.7$ & & shifting task & & \\
\hline & & & NW & & 48 & $22.1 \pm 1.9$ & $37.7 \pm 15.7$ & & & & \\
\hline & Banca, Harrison et & 2016 & BED & s & 32 & $34.7 \pm 5.6$ & $42.8 \pm 8.6$ & $\Phi^{\pi}$ & Intra-/Extradimensional set & $\mathrm{BED}>\mathrm{NW}, \mathrm{OW}=\mathrm{NW}$ & 5 \\
\hline & & & OW & & 31 & $32.7 \pm 3.4$ & $43.9 \pm 9.6$ & & shifting task & extradimensional errors & \\
\hline & & & NW & & 64 & $22.9 \pm 2.9$ & $43.5 \pm 10.9$ & & & & \\
\hline & Manasse, Forman et & 2015 & BED & $\star$ & 31 & $36.8 \pm 8.0$ & $45.1 \pm 14.9$ & ᄋ & Penn Condition Exclusion Task & $\mathrm{BED}=\mathrm{OW}$ & 6 \\
\hline & al. & & OW & & 43 & $37.9 \pm 6.3$ & $51.1 \pm 8.3$ & & & & \\
\hline & Reiter, Heinze et al. & 2017 & BED & & 22 & $28.3 \pm 6.6$ & $29.0 \pm 9.4$ & $\oint^{\pi}$ & Probabilistic Reversal Learning & $\mathrm{BED}>\mathrm{NW}$ switching & 5 \\
\hline & & & & $\star$ & & & & & Task & $\mathrm{BED}<\mathrm{NW}$ performance & \\
\hline & & & NW & & 22 & $26.1 \pm 4.4$ & $27.8 \pm 4.5$ & & & BED $>$ NW stochasticity of choices & \\
\hline & Banca, Harrison et & 2016 & BED & 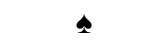 & 32 & $34.7 \pm 5.6$ & $42.8 \pm 8.6$ & $\Phi^{\pi}$ & Probabilistic Reversal Learning & Reversal phase: & 5 \\
\hline & al. & & OW & & 31 & $32.7 \pm 3.4$ & $43.9 \pm 9.6$ & & Task & $\mathrm{BED}=\mathrm{OW}=\mathrm{NW}$ overall & \\
\hline & & & NW & & 64 & $22.9 \pm 2.9$ & $43.5 \pm 10.9$ & & & $\mathrm{BED}<\mathrm{OW}$ in win condition & \\
\hline & & & & & & & & & & $\begin{array}{l}\mathrm{NW}<\mathrm{BED} \text { in loss condition (trials } \\
\text { to criterion) }\end{array}$ & \\
\hline & & & & & & & & & & NW $>$ BED less shifting after losses & \\
\hline & & & & & & & & & & in reversal compared to aquisition & \\
\hline & & & & & & & & & & BED $>$ NW more shifting after wins & \\
\hline & & & & & & & & & & in reversal compared to aquisition & \\
\hline & & & & & & & & & & $\mathrm{BED}>\mathrm{OW}$ win stay across & \\
\hline & & & & & & & & & & acquisition and reversal & \\
\hline
\end{tabular}


$\begin{array}{lrl}\text { Aloi, Rania et al. } & 2015 & \text { BED } \\ & & \text { NW } \\ \text { Duchesne, Mattos et } & 2010 & \text { BED }\end{array}$ al.

OW

Svaldi, Brand et al. 2010 BED OW

Reiter, Heinze et al. 2017 BED

NW

Dingemans,

Vanhaelen et al.

2019 BED DEP-

BED DEP +

NW

Galioto, Spitznagel et 2012 BED

al. OW

Aloi, Rania et al. 2020 BED

OW

NW

Duchesne, Mattos et 2010 BED

OW

Aloi, Rania et al.

Kelly, Bulik et al.

Dingemans,

Vanhaelen et al.

$$
2015 \text { BED }
$$

NW

2013 BED

NW

2019 BED DEP-

BED DEP+

NW

Blume, Schmidt et al. 2019 BED FA-

BED FA+

OW FA-

$\mathrm{OW} \mathrm{FA+}$
ه 45

$\begin{array}{ll}38 & 20.2 \pm 1.6 \\ & 35.9 \pm 2.9\end{array}$

$\begin{array}{lll}\star & 17-32.8 \pm 3.5\end{array}$

$\star \quad 22$

$30.7 \pm 3.9$

$28.3 \pm 6.6$

$26.1 \pm 4.4$

$\star \quad 25$

$38.5 \pm 7.4$

$37.6 \pm 6.2$

$23.5 \pm 2.8$

41
$-\quad 95.4 \pm 6.1$
$\quad 90 \quad 44.9 \pm 6.6$

- $\quad 35 \quad 38.9 \pm 6.9$

$36.4 \pm 6.8$

$23.0 \pm 0.8$

$35.9 \pm 2.9$

$36.6 \pm 3.8$

$35.2 \pm 6.5$

$20.2 \pm 1.6$

$24.5 \pm 5.1$

$23.4 \pm 5.2$

$38.5 \pm 7.4$

$37.6 \pm 6.2$

$23.5 \pm 2.8$

$41.9 \pm 5.3$

$42.2 \pm 6.1$

$42.8 \pm 4.8$

$44.1 \pm 6.6$
$38 \quad 36.6 \pm 3.8$
$\star \quad 17 \quad 32.8 \pm 3.5$
$30.6 \pm 10.9$

$25.6 \pm 3.5$

$33.3 \pm 5.0$

$35.4 \pm 7.9$

$42.4 \pm 12.3$

$38.3 \pm 13.1$

$29.0 \pm 9.4$

$27.8 \pm 4.5$

$32.8 \pm 8.5$

$34.2 \pm 9.9$

$36.7 \pm 12.3$

$43.6 \pm 11.5$

$41.2 \pm 10.4$

$44.2 \pm 10.7$

$49.6 \pm 9.9$

$46.7 \pm 11.1$

$33.3 \pm 5.0$

$35.4 \pm 7.9$

$30.6 \pm 10.9$

$25.6 \pm 3.5$

$19.3 \pm 1.7$

$19.0 \pm 1.3$

$32.8 \pm 8.5$

$34.2 \pm 9.9$

$36.7 \pm 12.3$

$38.8 \pm 9.4$

$37.5 \pm 10.1$

$40.5 \pm 10.9$

$43.4 \pm 10.4$
BED $>$ NW time, errors

Ф) Trail Making Task B

$\mathrm{BED}=\mathrm{OW}$ time

5

ㅇ Trail Making Task B

Trail Making Task B

Trail Making Task B-A

(computerised)

Trail Making Task B-A

(computerised)

Trail Making Task B, Trail

Making Task B-A

Wisconsin Card Sorting Task

$\mathrm{BED}<\mathrm{NW}$

$\mathrm{BE}=\mathrm{NW}$

$\mathrm{BED}(\mathrm{DEP}+)=\mathrm{BED}(\mathrm{DEP}-)=\mathrm{NW}$

$\mathrm{BED}(\mathrm{FA}+)=\mathrm{BED}(\mathrm{FA}-$

)$=\mathrm{OW}(\mathrm{FA}+)=\mathrm{OW}\left(\mathrm{FA}_{-}\right)$

perseverative errors

$\mathrm{BED}(\mathrm{FA}+)=\mathrm{BED}(\mathrm{FA}-$

)$<\mathrm{OW}(\mathrm{FA}+)=\mathrm{OW}(\mathrm{FA}-)$ learning to learn

\begin{tabular}{|c|c|c|c|c|c|c|c|}
\hline B. Authors & Year & Group & $\mathrm{N}$ & Species & Sex & Paradigm & Main Findi \\
\hline Rossetti, Spena et al. & 2013 & $\begin{array}{l}\mathrm{BE} \\
\mathrm{CON}\end{array}$ & $\begin{array}{l}16 \\
14\end{array}$ & Rats & 우 & Aversive conditioning & $\mathrm{BE}<\mathrm{CON}$ \\
\hline Moshe, Bekker et al. & 2017 & $\mathrm{BE}$ & 23 & Rats & 우 & Aversive conditioning & $\mathrm{BE}<\mathrm{CON}$ \\
\hline
\end{tabular}


CON

Oswald, Murdaugh et 2011 BE

al.

CON

Velázquez-Sánchez, 2015 BE

Santos et al. CON

Heal, Goddard et al. $2016 \quad \mathrm{BE}$

$\mathrm{BE}$
$\mathrm{CON}$

Chawla, Cordner et 2017 BE

al.

16

10

Rats

을 $\quad$ Aversive conditioning

$\mathrm{BE}<\mathrm{CON}$

Rats

onersive conditioning

$\mathrm{BE}<\mathrm{CON}$

15 Rats

을 $\quad$ Aversive conditioning

$\mathrm{BE}<\mathrm{CON}$

Rats

$\sigma^{7}$

Barnes maze (reversal learning)

$\mathrm{BE}>\mathrm{CON}$ (perseveration)

$\mathrm{BE}(\mathrm{D})$ - Binge eating (disorder), OW - overweight/obese, NW - normal weight, FA - food addiction, DEP - depression, CON - control, $\star$ - Eating disorder examination interview,

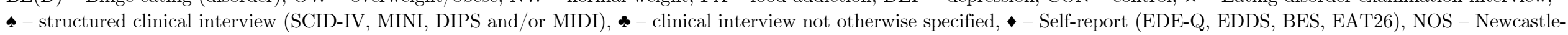
Ottawa Scale, BMI summary statistics for Kittel, Schmidt et al. (2017) are in percentiles. 